\title{
How Does COVID-19 Affect Traffic on Highway Network: Evidence from Yunnan Province, China
}

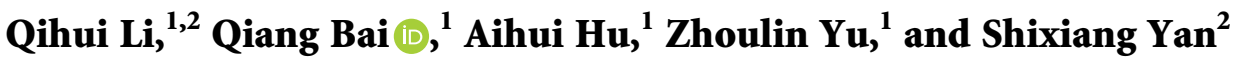 \\ ${ }^{1}$ College of Transportation Engineering, Chang'an University, Xi'an 710064, China \\ ${ }^{2}$ Research Institute of Highway Science and Technology of Yunnan Province, Kunming 650051, China \\ Correspondence should be addressed to Qiang Bai; qiang.bai@chd.edu.cn
}

Received 14 August 2021; Revised 21 December 2021; Accepted 31 January 2022; Published 28 February 2022

Academic Editor: Jaeyoung Lee

Copyright $\odot 2022$ Qihui Li et al. This is an open access article distributed under the Creative Commons Attribution License, which permits unrestricted use, distribution, and reproduction in any medium, provided the original work is properly cited.

\begin{abstract}
The COVID-19 pandemic and antipandemic policies have significantly impacted highway transportation. Many studies have been conducted to quantify these impacts. However, quantitative analysis of the impacts on province-wide traffic in developing countries, such as China, is still inadequate. This paper tried to fill this gap by proposing equations to quantify the traffic variations of overall provincewide traffic and to analyze the intercity bus traffic variation and intercity bus usage, applying the K-means cluster method to conduct the analysis of traffic reductions in regions with different levels of economic development, and using the hypothesis testing for traffic recovery analysis. It is found that passenger vehicle traffic and truck traffic dropped by $59.67 \%$ and $68.19 \%$ during the outbreak, respectively. The intercity bus traffic on highways declined by $59.8 \%$ to $98.6 \%$, and the intercity bus usage dropped by $55.6 \%$ on average. For traffic reductions in different regions, the higher the GDP per capita was, the more the traffic was affected by the pandemic. In regions with lower GDP per capita, traffic variations were minor. It is also found that the passenger vehicle traffic went through four stages in 99 days: the Decline Stage, Rapid Recovery Stage, Slow Recovery Stage, and Normal Stage, while truck traffic only experienced the Decline Stage, Rapid Recovery Stage, and Normal Stage and took 51 days to recover to the Normal Stage. In the Rapid Recovery Stage, the recovery rates were $15.6 \%$ and $12.9 \%$ per week for passenger vehicle traffic and truck traffic, respectively, and the recovery rate was only $2.1 \%$ for passenger vehicle traffic in the Slow Recovery Stage. Despite the recovery of traffic volumes, neither passenger-kilometers nor tonne-kilometers of freight in 2020 reached the same level as in 2019. These findings help the understanding of the pandemic's impacts on highway traffic for researchers and can provide valuable references for decision-makers to develop antipandemic policies.
\end{abstract}

\section{Introduction}

Since December 2019, the rapid spread of the COVID-19 pandemic has brought about a series of problems to the international community. The outbreak of COVID-19 has affected daily human activities and produced incalculable impacts on various industries. It brought challenges not only to medical and public health management but also to other areas such as governance and transportation [1]. Although the pandemic has been going on for more than one year, it is still horrible in many countries. For instance, in South Asia, the World Health Organization (WHO) reported that the number of confirmed cases increased again in an explosive manner, with more than 300,000 new cases per day in May 2021 [2]. Recently, the COVID-19 Delta variant spread quickly and has caused new changes to the world. Therefore, the pandemic is far from over.

Most countries have experienced varying degrees of impact from the pandemic and adopted different levels of antipandemic measures. In China, despite the strict antipandemic policies being taken at the early stage of the outbreak, there were still 90,604 confirmed cases and 4,739 deaths as of October $4^{\text {th }}, 2020$ [3]. Fortunately, the spread of the pandemic was contained timely in China. In South Korea, a total number of 9,786 confirmed cases were reported by the end of March of 2020 [4], which disrupted daily life and caused severe damage to the economy [5]. Some other countries, such as the U.K., Italy, and Spain, experienced significant economic downturns and many confirmed cases under the loose pandemic prevention policy 
[6]. To reduce the spread of the pandemic, the WHO has made recommendations of wearing masks, maintaining social distance, and reducing gatherings [7]. In addition, some local governments had changed their antipandemic policies from loose to strict. The local governments also declared city lockdowns and travel restrictions for some cities with severe outbreaks. Some evidence from the studies had shown that travel restrictions played a crucial role in controlling the spread of the pandemic, especially in the early stage of the outbreak [8]. However, these measures and policies would have an impact on the transportation system.

Many studies have been conducted to analyze the impacts of COVID-19 on transportation systems from different perspectives. For instance, several studies have investigated the traffic variation during the outbreak, traffic recovery, mobility, and traffic safety from a province-level or a national-level perspective [9-13]. Traffic reduction and changes in urban mobility behaviors also have been studied [14]. In addition, due to the recommendation of keeping social distance, people's attitudes towards public transportation and travel patterns also become hot study topics $[15,16]$. In China, there are also some studies on the assessment of the impacts of COVID-19, but most of them mainly focus on urban traffic. For example, Zhou et al. combined the Event Study Methodology and Empirical Mode Decomposition to evaluate the impacts of antipandemic policies on traffic in Beijing [17]. In the study, the proposed method described how the traffic flow was supposed to be if the pandemic did not occur. Besides, there is a study about the influence of the pandemic on ride-sourcing and taxi markets [18]. The spatial structure evolution of population flow in cities with different traffic control situations has also been explored [19]. And another study investigated the situations of people's travel frequency and travel modes during the pandemic [20]. Few studies assess the province-wide impacts on traffic of highway networks. Therefore, to fill this gap, this study aims to analyze the impacts of antipandemic policies on province-level highway transportation system, which would help researchers and decision-makers understand the impacts better on provincewide highway traffic in China.

The study will try to answer the following questions: how has the highway traffic been affected during the outbreak of COVID-19? How has intercity public transportation changed during the outbreak of COVID-19? What are the differences in the extent to which traffic is affected in regions with different levels of economic development? How long did it take to recover? Correspondingly, four main issues are examined: (1) the province-wide traffic variations on highways during the outbreak; (2) the traffic variations and usage of intercity public transportation during the outbreak; (3) the traffic variations in different regions with different levels of economic development; and (4) the time required for the recovery of highway traffic.

This paper is organized as follows. Section 2 reviews the existing studies on four aspects: traffic variations during the outbreak of COVID-19; traffic variations and usage of intercity public transportation; traffic variations in different regions with different levels of socio-economic development; and the process of traffic recovery. Section 3 presents methods adopted to conduct analyses in this paper. Section 4 introduces the study area, confirmed cases of COVID-19, and the antipandemic policies. Section 5 illustrates the results of four aspects mentioned in Section 2. Section 6 discusses the findings, compares them with existing studies, and provides suggestions. Finally, Section 7 summarizes the key findings and provides the directions for future study.

\section{Literature Review}

The COVID-19 and the antipandemic policies caused a significant decline in traffic. For instance, studies show that traffic volumes had already reduced significantly before the stay-at-home order and dropped further after the order went into effect [21]. In addition, the study in Qatar assessed the impacts of pandemic response measures on traffic mobility by quantifying the holistic impacts on traffic volume and traffic safety [6]. It is found that traffic volume declined more with more antipandemic policies implemented, which is a $6.2 \%$ decline with one antipandemic policy implemented, $22.6 \%$ with two, and $30.4 \%$ with three. This illustrates the effectiveness of combining multiple antipandemic policies. Therefore, the antipandemic policy is a key element that contributed to the drop in traffic.

Traffic variations depend not only on the antipandemic policies but also on levels of economic development. Similar policies in different countries with different levels of economic development could lead to different levels of impacts. Several studies have tried to quantify these impacts. In the United States, a study assessed traffic reduction after implementing stay-at-home orders in North Carolina and Virginia, which shows a decline in traffic up to $40 \%$ [22]. In addition, evidence from Florida also shows a dramatic drop of $47.5 \%$ in overall state-wide traffic after implementing state-wide policies to limit person-to-person interaction [10]. In Europe, stay-at-home orders also had a considerable impact on traffic. Italy imposed a nationwide lockdown on March $12^{\text {th }}$ of 2020 to deal with a surge in confirmed cases. As a result, it caused a $50 \%$ reduction in the total number of trips between Italian provinces [23]. A similar phenomenon occurred in Spain: overall mobility fell by 76\% [24]. Asian countries, such as South Korea, experienced less reduction in traffic, with only a maximum of $26.1 \%$ decrease during the outbreak of COVID-19 [25]. Obviously, after implementing the antipandemic policies, a significant drop in traffic was inevitable [26]. It is noteworthy that most studies about the state-wide or country-wide traffic variation come from developed countries; studies about state-wide traffic reduction from developing countries are rare. Therefore, there is a need to study the traffic variation in developing countries during the outbreak of COVID-19.

The COVID-19 pandemic and antipandemic policies cause the reduction in traffic and raise concerns about hygiene in public transportation, which makes people use them less. A study in Australia shows great concern about public transportation hygiene issues under a policy imposing travel restrictions and social distancing, causing a decline of $53 \%$ in public transportation usage [15]. In Colombia, it is 
found that the reduction in public transportation demand was between $90 \%$ and $80 \%$ during the pandemic [16]. Besides, Lee et al. [14] also found that people's behavior is sensitive to the COVID-19 severity in developing countries [14]. Most travellers are public transportation-dependent in some developing countries [27]. Therefore, concerns about hygiene in public transportation are widespread and seem to be more pronounced in developing countries. However, existing studies mainly focus on urban public transportation. Few studies have addressed intercity public transportation on highways, so the impacts of COVID-19 on intercity public transportation are still an area that needs to be studied.

When the pandemic was severe, some governments would impose strict antipandemic policies. These policies caused a dramatic decline in traffic in the short run, and then the traffic would recover after the policies were relaxed. The recovery of traffic after strict antipandemic policies was cancelled and is also of interest to decision-makers and researchers. The time needed for recovery varies from region to region. For example, in North Carolina and Virginia, the average weekly recovery rate of traffic volume was in a range of $2.3 \%-3.4 \%$ per week [28]. However, by the time, the study has been finished, and the average traffic still had not entirely returned to normal [28]. Therefore, although the traffic has trended back after the policy was eased, it is hard to return to preoutbreak status within a few months. Few studies have depicted the whole process of traffic returning to normal.

In a nutshell, many studies have been conducted to evaluate the impacts of COVID-19 on traffic. However, the impacts of COVID-19 on highway traffic in developing countries have not been well studied. Therefore, this paper devotes to provide valuable findings to illustrate the impacts on province-wide highway traffic in China from four aspects: the traffic variations on highways during the outbreak; the traffic variations and usage of highway intercity public transportation during the outbreak; traffic variations in regions with different levels of socio-economic development; and the whole process of traffic recovery.

\section{Methods}

3.1. Traffic Variation Quantification. Many studies have been conducted to quantify the impacts of COVID-19 on traffic. The traffic variation is typically used to measure the impacts. Since the impacts of the COVID-19 occurred in 2020, many studies chose 2019 traffic data as the historical baseline data for comparison. For example, equation (1), which calculates the percentage of change in traffic from 2019 to 2020, was applied to evaluate the impacts of COVID19 on traffic in North Carolina and Virginia [28]. Some similar studies in different countries also adopted similar metrics to evaluate traffic reduction $[6,25]$. However, in some areas where the 2019 data cannot be obtained, the data before the pandemic outbreak were used as the baseline data to evaluate the traffic variation [21]. In addition, the predicted traffic volume based on historical data with the assumption of the absence of COVID-19 can also be used as the baseline [17].

$$
T_{\text {Change }}=\frac{\text { Traffic }_{2020}-\text { Traffic }_{2019}}{\text { Traffic }_{2019}} \times 100 \%,
$$

where $T_{\text {Change }}$ is the traffic variation and Traffic $_{2020}$ and Traffic $_{2019}$ are the daily traffic volume in 2020 and 2019, respectively.

Traffic variations in three periods, as presented in Table 1, are calculated to evaluate the impacts of COVID-19 on traffic. Specifically, equation (2) is used to compare the traffic volumes at each traffic count station before, during, and after the outbreak in Phase I. Equation (3) is used to analyze the average traffic reduction for a region in Period II. Equation (4) is applied to calculate the average traffic variation for a specific day in Period III to show the traffic recovery throughout the entire year.

$$
R_{p j}^{t}=\frac{\bar{V}_{2020 p j}^{t}-\bar{V}_{2019 p j}^{t}}{\bar{V}_{2019 p j}^{t}} \times 100 \%,
$$

where $R_{p j}^{t}$ is the traffic variation of vehicle type $t$ at traffic count station $j$ in phase $p, \quad p \in\{1,2,3\}$; $t \in\{$ passenger vehicle, truck $\} ; j$ is the traffic account station index; and $\bar{V}_{2019 p j}^{t}$ and $\bar{V}_{2020 p j}^{t}$ are the average daily traffic volumes of station $j$ in phase $p$ in 2019 and 2020 , respectively.

$$
R_{q c}^{t}=\frac{\sum_{j}\left(\bar{V}_{2020 q j_{c}}^{t}-\bar{V}_{2019 q j_{c}}^{t}\right)}{\sum_{j_{c}} \bar{V}_{2019 q j_{c}}^{t}} \times 100 \%,
$$

where $R_{q c}^{t}$ is traffic variation of vehicle type $t$ at traffic count station $j$ in the $q^{\text {th }}$ quarter; $j_{c}$ is the traffic count station index in region (or province) $c$; and $\bar{V}_{2019 q_{c}}^{t}$ and $\bar{V}_{2020 q j_{c}}^{t}$ are the average daily volume at traffic count station $j_{c}$ in the region (or province) $c$ in the $q^{\text {th }}$ quarter of 2019 and 2020, respectively.

$$
\overline{R_{d j}^{t}}=\frac{1}{n} \times \sum_{j=1}^{n} \frac{V_{2020 d j}^{t}-\bar{V}_{2019 j}^{t}}{\bar{V}_{2019 j}^{t}} \times 100 \%,
$$

where $\overline{R_{d j}^{t}}$ is the average traffic variation of vehicle type $t$ at all traffic count stations in the specific day $d ; V_{2020 d j}^{t}$ is the daily traffic volume in the date $d$ of traffic count station $j$; $\bar{V}_{2019 j}^{t}$ is the average daily traffic in traffic count station $j$; and $n$ is the number of traffic count stations.

Period I, also called the outbreak period, refers to the Spring Festival travel rush (40 days) starting from January $10^{\text {th }}$ to February $18^{\text {th }}$ of 2020 . The Spring Festival travel rush refers to a phenomenon that a large number of passengers return to their hometown before the Spring Festival (a nationwide holiday of China) and back to their workplace after the Spring Festival, which caused a high pressure on the transportation system. To better understand the traffic variations before, during, and after the outbreak of pandemic [14], Period I can be further divided into three phases, as shown in Table 2. Spring Festival is the most important festival in China. Its corresponding Gregorian calendar dates differ from year to year because it is based on the Chinese lunar calendar. Hence, the dates of the Spring Festival travel rush period also change every year. However, although the dates are different, the traffic characteristics during this 
TABle 1: Time horizon of study.

\begin{tabular}{lcc}
\hline Period code & Period name & Focus \\
I & The outbreak period (40 days) & Traffic variation before, during, and after the outbreak (Phase 1, Phase 2, and Phase 3) \\
II & The first quarter of 2020 & Traffic variation in different cities with various levels of development \\
III & The entire year of 2020 & Recovery of traffic in 2020 \\
\hline
\end{tabular}

Table 2: Three phases in Period I.

\begin{tabular}{|c|c|c|c|c|}
\hline Phase & Time horizon & Dates in 2019 & Dates in 2020 & Notes \\
\hline 1 & Before Spring Festival Holiday & Jan. $21^{\text {st }}$ to Feb. $3^{\text {rd }}$ & Jan. $10^{\text {th }}$ to Jan. $23^{\text {rd }}$ & Nonholiday \\
\hline 2 & During Spring Festival Holiday & Feb. $4^{\text {th }}$ to February $20^{\text {th }}$ & Jan. $24^{\text {th }}$ to Feb. $9^{\text {th }}$ & Holiday \\
\hline 3 & After Spring Festival Holiday & Feb. $20^{\text {th }}$ to March $1^{\text {st }}$ & Feb. $10^{\text {th }}$ to Feb. $18^{\text {th }}$ & Nonholiday \\
\hline
\end{tabular}

particular period in different years are similar and still comparable. Therefore, the traffic in the Spring Festival travel rush in 2019 was selected to compare with that in 2020.

As shown in Table 2, in 2020, Phase 1 started from January $10^{\text {th }}$ to January $23^{\text {rd }}$. During this phase, most people were not yet aware of the pandemic. Therefore, the traffic was similar to that before the pandemic. Phase 2 was the lockdown phase starting from January $24^{\text {th }}$ to February $9^{\text {th }}$. Most people stayed at home during Spring Festival and reduced travel since January $24^{\text {th }}$ even though the government only issued an official announcement on January $28^{\text {th }}$ to reduce travel. Strict antipandemic policies were implemented during this phase, and traffic volumes dropped significantly. In Phase 3, from February $10^{\text {th }}$ to February $18^{\text {th }}$, some people went back to work, but strict antipandemic policies were still in place.

In order to quantify the changes in traffic at each of these periods, around two years of traffic count data from 168 traffic count stations distributed in Yunnan Province were collected for the study. The locations of the traffic count stations are shown in Figure 1. The data in 2019 cover January 2019 to September 2019 and December 2019; the data in 2020 cover the whole year. Each station counts the traffic for each type of vehicle at a five-minute interval. The traffic count stations collect two types of traffic data: passenger vehicle traffic and truck traffic. Typically, the COVID19 has different impacts on passenger vehicle traffic and truck traffic. Therefore, the results of passenger vehicle traffic and truck traffic variations are presented, respectively.

3.2. Impact Analysis Methods. In this paper, several forms of figures are used to present the collected data, such as line graphs, box plots, and bar graphs. Methods of cluster analysis and hypothesis testing were adopted to analyze the data. Before conducting the cluster analysis, the data are normalized using the $\mathrm{z}$-score method and then clustered by the K-means clustering method. In addition, the hypothesis testing method is used to analyze the differences between groups of data.

3.2.1. Clustering Method. The K-means clustering method is a widely used approach to classify the samples based on their attributes [29]. In the K-means clustering method, the samples are divided into specified clusters by the size of the distance between each sample. The principle of classification is to keep all points within the same cluster as close as possible while keeping cluster-to-cluster distances as far as possible [30]. The equations of the clustering algorithm are shown in equations (5) and (6).

$$
\begin{aligned}
w_{j} & =\frac{\sum_{i_{l} \in C_{j}} i_{l}}{\left|C_{j}\right|}, \\
E & =\sum_{j=1}^{k} \sum_{i_{l} \in C_{j}}\left|i_{l}-w_{j}\right|^{2},
\end{aligned}
$$

where $k$ means the number of clusters; $i_{l}$ indicates the element in $\left\{i_{1}, i_{2}, i_{3}, \ldots, i_{n}\right\}$, which belongs to the specified cluster $C_{j} ; C_{j}$ is the cluster that belongs to a set of clusters $\left\{C_{1}, C_{2}, C_{3}, \ldots, C_{k}\right\}$ with the set of centroids $\left\{w_{1}, w_{2}, w_{3}, \ldots, w_{k}\right\}$; and $E$ is the error function.

The traffic volume always correlates to the socio-economic activities of human beings. For instance, during the lockdown, since the socio-economic activities of residents were restricted, people had to give up some unnecessary travel, such as those for tourism, leisure, and entertainment purposes [31]. Therefore, regional economic data in Yunnan Province during Period II in 2020 were collected from the Yunnan Provincial Bureau of Statistics to explore their relationship with traffic volume changes [32].

Using SPSS software, K-means clustering was adopted to explore the impacts of COVID-19 on traffic in different regions with different economic development levels. Five indicators were selected for clustering, including per capita GDP, GDP growth rate, the total number of confirmed cases, reduction in passenger vehicle traffic, and reduction in truck traffic. The reductions in passenger vehicle traffic and truck traffic were calculated using equation (3). The data of each region are shown in Table 3.

3.2.2. Hypothesis Testing. Hypothesis testing is a widely used method for statistical inference [33]. This method can determine whether the results of a survey or an experiment are significant and can test the difference between two data groups. Parr et al. [10] applied the $t$-test to check whether there existed a difference in traffic volume before and after 


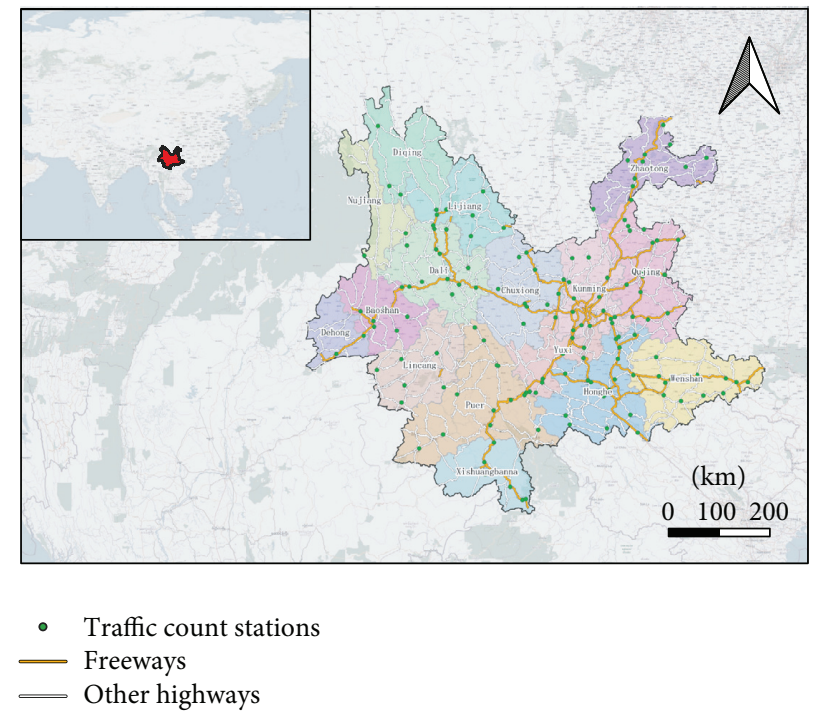

Figure 1: Locations of traffic count stations in Yunnan Province.

the pandemic occurred, thus to determine whether the traffic was affected by COVID-19 [10].

In this study, a left-tailed test is adopted to test whether traffic has recovered from the pandemic of COVID-19 by comparing the traffic in 2019 and 2020. Before the testing, the distribution test was performed to ensure the availability of the data for the left-tailed test. The percentages of change in traffic for both passenger vehicles and trucks follow normal distributions. In the test, the null hypothesis assumes that the traffic volume has recovered (equation (7)), while the alternative hypothesis is that the traffic volume has not recovered (equation (8)).

$H_{0}$ : the mean of all variations of all stations $\geq 0$,

$$
H_{1} \text { : the mean of all variations of all stations }<0 \text {. }
$$

\section{Antipandemic Policies in Yunnan Province}

4.1. Introduction for Yunnan Province, China. Yunnan Province is located in the southwest of China (Figure 1) and borders Vietnam, Laos, and Myanmar. The total area of Yunnan Province is around 394.1 thousand square kilometers with 16 regions, with Kunming as the provincial capital. By the end of 2020, the census data showed that the population of Yunnan was 47.21 million [34]. The highway network plays a key role in ensuring the operation of economic activities between cities [35]. By the end of 2019, the highway mileage of Yunnan Province was 231.74 thousand kilometers [36].

4.2. COVID-19 Cases and Antipandemic Policies. The new confirmed cases and active cases of COVID-19 data from January $19^{\text {th }}$ to March $18^{\text {th }}$ of 2020 in Yunnan Province were collected [37], as shown in Figure 2. It is seen that during this period, the pandemic in Yunnan Province experienced a surge in the number of new confirmed cases and reached a peak and then declined to none under antipandemic policies. The antipandemic policies [38] that the government took were also collected, as shown in Figure 3, with detailed information presented in Table 4.

The first official antipandemic policy to reduce travel and gathering was released on January $28^{\text {th }}$, when the number of new confirmed cases was at its peak. Then, according to the second policy released on February $29^{\text {th }}$ [38], except for industries involved in ensuring the operation of public utilities (such as water supply, power supply, and public transportation), industries for pandemic prevention and control (such as medical device and medicine production), and industries for daily life (such as supermarkets and food production), all other types of industries could not resume work earlier than February $9^{\text {th }}$. This policy means that the cities were almost in lockdown between January $29^{\text {th }}$ and February $9^{\text {th }}$, most businesses stopped, and people were recommended to stay home.

\section{Impacts of COVID-19 on Highway Traffic}

The results contain three parts corresponding to traffic changes in three periods, respectively. First, in Period I, the study focuses on province-wide traffic variation during the three phases, and the traffic variation and usage of the intercity bus will be presented. Second, in Period II, the traffic variations in different levels of economic development will be analyzed using the cluster method. Third, the last part will concentrate on the process of traffic recovery in Period III, which contains the traffic recovery in all traffic count stations and recovery of passenger and freight transportation.

5.1. Impacts of COVID-19 on Traffic during Three Phases in Period I. Period I is unique not only because the pandemic occurred during this period but also because of the particular traffic characteristics and the traffic pressure brought about by the nationwide holiday. The traffic characteristics are typically significantly different from those of other times. 
TABLe 3: Data for cluster analysis.

\begin{tabular}{|c|c|c|c|c|c|}
\hline Region & $\begin{array}{l}\text { Per capita GDP } \\
(\mathrm{CNY})\end{array}$ & $\begin{array}{l}\text { The growth rate of } \\
\text { GDP }(\%)\end{array}$ & $\begin{array}{c}\text { Reduction in passenger vehicle } \\
\text { traffic }(\%)\end{array}$ & $\begin{array}{l}\text { Reduction in truck } \\
\text { traffic }(\%)\end{array}$ & $\begin{array}{c}\text { Total confirmed } \\
\text { cases }\end{array}$ \\
\hline Kunming & 22092 & -5.6 & -28.9 & -35.1 & 60 \\
\hline Yuxi & 18884 & -2.9 & -32.3 & -35.7 & 14 \\
\hline Diqing & 14430 & 0.3 & -33.6 & -26.5 & 0 \\
\hline Xishuangbanna & 9656 & -10 & -27.2 & -23.5 & 15 \\
\hline Honghe & 10439 & -3.6 & -30.8 & -22.7 & 9 \\
\hline Chuxiong & 10478 & 0.3 & -28.6 & -50.9 & 4 \\
\hline Qujing & 9763 & 1.1 & -10.8 & -11.7 & 13 \\
\hline Dehong & 9012 & -1.6 & -41.0 & -41.4 & 5 \\
\hline Dali & 7962 & -11.4 & -29.9 & -33.6 & 13 \\
\hline Baoshan & 7466 & -9.9 & -29.0 & -22.9 & 9 \\
\hline Lijiang & 8020 & -3.5 & -26.7 & -11.2 & 7 \\
\hline Nujiang & 6761 & -13.9 & -11.3 & -23.5 & 0 \\
\hline Puer & 6716 & -13.8 & -31.2 & -34.0 & 4 \\
\hline Lincang & 5777 & -3.7 & -18.9 & -9.0 & 1 \\
\hline Wenshan & 6547 & -0.5 & -21.1 & -17.3 & 2 \\
\hline Zhangtong & 4729 & -2.9 & -11.4 & -12.1 & 25 \\
\hline
\end{tabular}

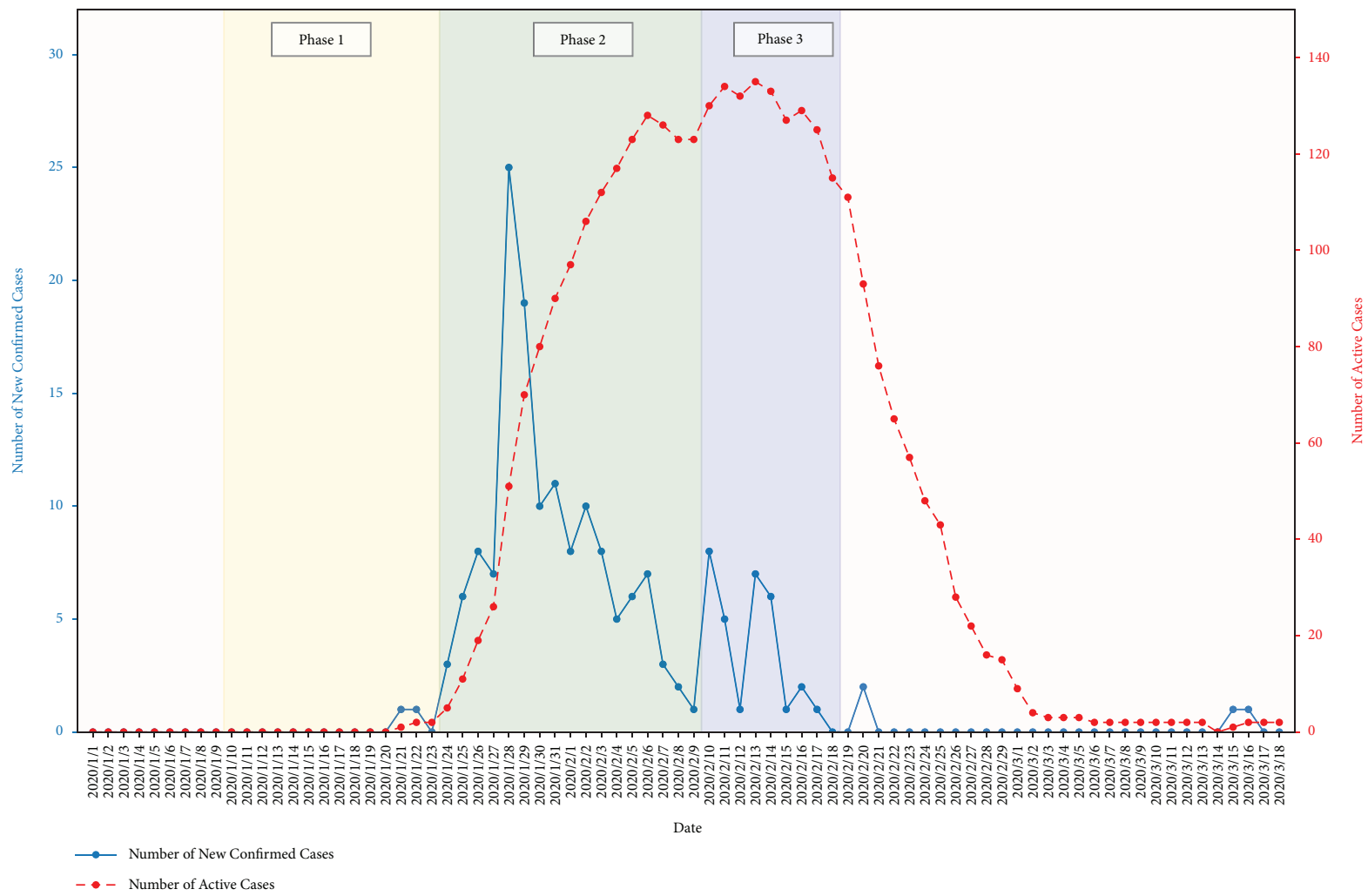

Figure 2: COVID-19 cases in Yunnan Province, China.

That is, most people are on holiday. There is typically rare traffic for work commuting but more for tours, family visits, and recreational commuting. However, the outbreak of COVID-19 has seriously affected the traffic.

5.1.1. Province-Wide Traffic Variation. To quantify the traffic differences in different phases (Table 2), the traffic variation at each traffic count station for each phase was calculated using equation (2). The traffic variations of all stations have been presented by a boxplot shown in Figure 4 . The province-wide distribution of traffic variations in three phases is presented in Figures 5 -7 .

Before the outbreak of pandemic, as shown in Phase 1, the average growth rates of traffic in the traffic count stations are $1.85 \%$ for passenger vehicles and $10.91 \%$ for trucks, as shown in Figure 4 . The result indicates that traffic slightly increased in the first phase of Period I in 2020, compared with that in 2019. It is seen from Figure 5 that, in this phase, only a few newly confirmed cases occurred in Kunming, the 


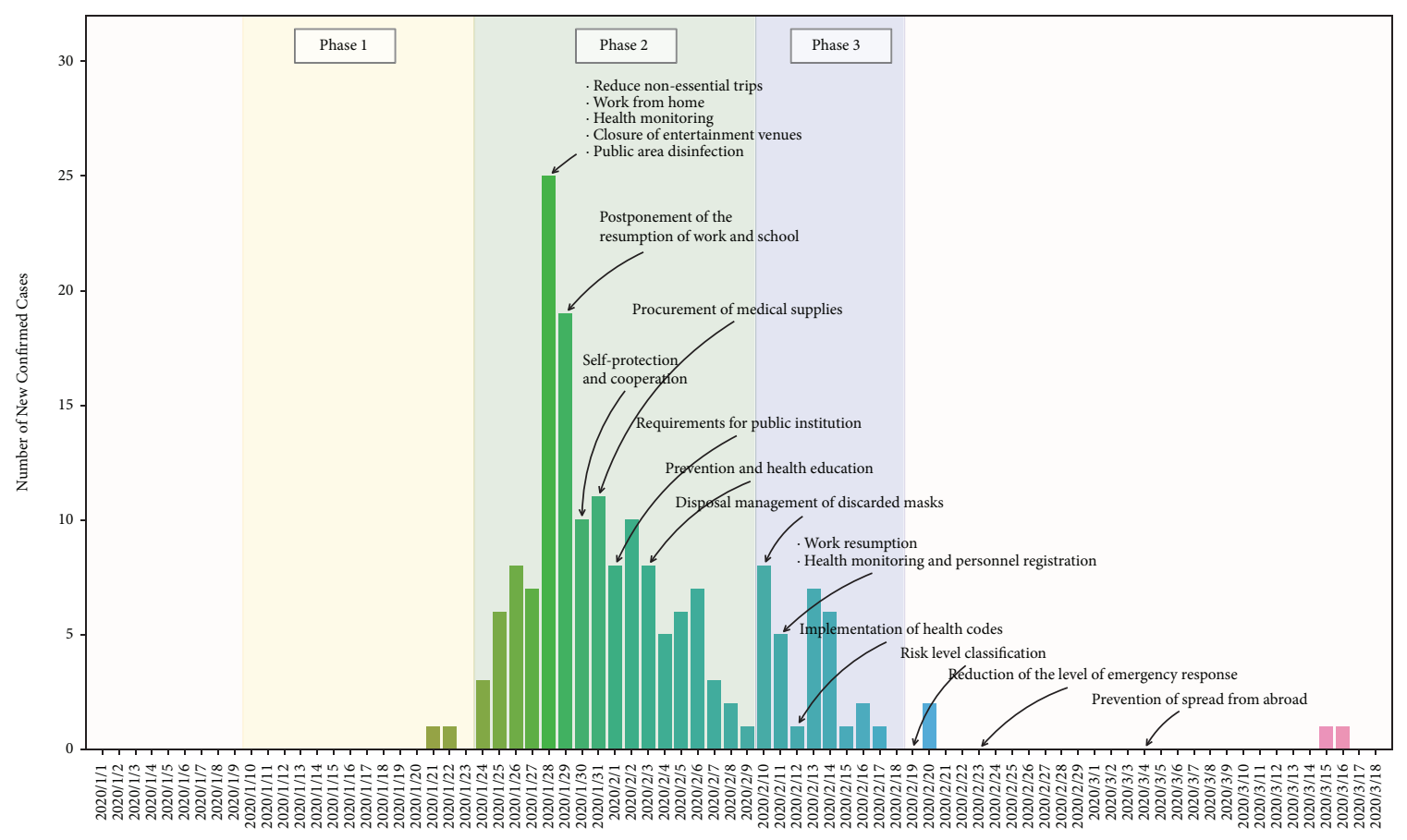

Date

FIgURE 3: Daily new confirmed cases in Yunnan province.

Table 4: Antipandemic policies in Yunnan Province.

\begin{tabular}{|c|c|c|c|c|}
\hline Dates & $\begin{array}{l}\text { \# of new } \\
\text { confirmed } \\
\text { cases }\end{array}$ & $\begin{array}{c}\text { Policy } \\
\text { number }\end{array}$ & Measures & Detailed information \\
\hline
\end{tabular}

No. 1

Reduce nonessential trips; work from home; health monitoring; closure of entertainment venues; public area disinfection

$\begin{array}{lll}\begin{array}{l}2020 / \\ 1 / 29 \\ 2020 /\end{array} & 19 & \text { No. } 2 \\ 1 / 30 & 10 & \text { No. } 3 \\ 2020 / & 11 & \text { No. } 4 \\ 1 / 31 & & \\ 2020 / & 8 & \text { No. } 5 \\ 2 / 1 & & \text { No. } 6 \\ 2020 / & & \text { No. } 7 \\ 2 / 3 & & \\ 2020 / & 8 & \text { No. } 8 \\ 2 / 10 & 8 & \text { No. } 9 \\ 2020 / & & \end{array}$

Postpone resumption of commercial companies and schools

Call on self-protection and cooperation with government

Procurement of medical supplies

Requirements for public institutions

Health education

Disposal management of discarded masks

Resumption of work and production; health monitoring for newcomers

Implementation of health codes
Recommendation for people to reduce nonessential trips; work online from home to reduce travel; set up health monitoring points at transportation hubs to check passengers' temperature; identify people who have close contacts with infected people; suspend the operation of public entertainment venues such as the park, museum, Internet bar, and dance hall; disinfect public places and public transportation Businesses and schools were asked to delay openings after the Spring Festival holiday

The government called on the people to take selfprotection and cooperate with the government's antipandemic policies

The government announced the notification for purchasing the medical supplies for pandemic prevention

The government announced the pandemic prevention and control requirements for public institutions

Call for COVID-19 prevention and health education

Disposal management of discarded masks to prevent the spread of medical waste

Resumption of work and production; collection of the health status of people who came to Yunnan Province

Health codes were required for use in public places, including taking public transportation 
TABle 4: Continued.

\begin{tabular}{|c|c|c|c|c|}
\hline Dates & $\begin{array}{c}\text { \# of new } \\
\text { confirmed } \\
\text { cases }\end{array}$ & $\begin{array}{c}\text { Policy } \\
\text { number }\end{array}$ & Measures & Detailed information \\
\hline $\begin{array}{l}2020 / \\
2 / 19\end{array}$ & 0 & No. 10 & Risk level classification & $\begin{array}{l}\text { Risk level classification of COVID-19 for all } \\
\text { counties }\end{array}$ \\
\hline $\begin{array}{l}2020 / \\
2 / 23\end{array}$ & 0 & No. 11 & Reduction of the level of emergency response & $\begin{array}{l}\text { Reduced the level of emergency response from Level } \\
\qquad 1 \text { to Level } 3\end{array}$ \\
\hline $\begin{array}{l}2020 / \\
3 / 4\end{array}$ & 0 & No. 12 & Prevention of spread from abroad & $\begin{array}{l}\text { Issued a policy to prevent the COVID-19 cases from } \\
\text { abroad }\end{array}$ \\
\hline
\end{tabular}

Note. The antipandemic policies were collected from the website of the People's Government of Yunnan Province [38].

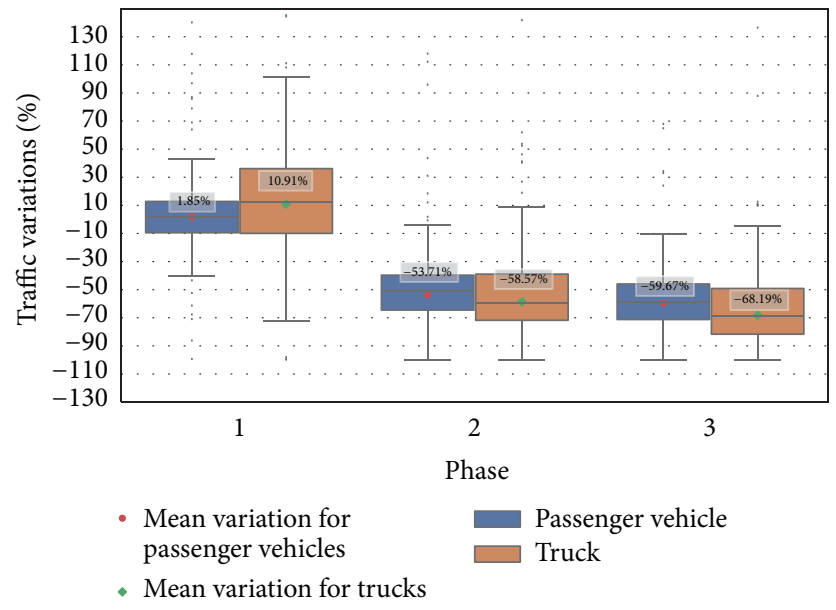

FIgURE 4: Traffic variations in three phases.

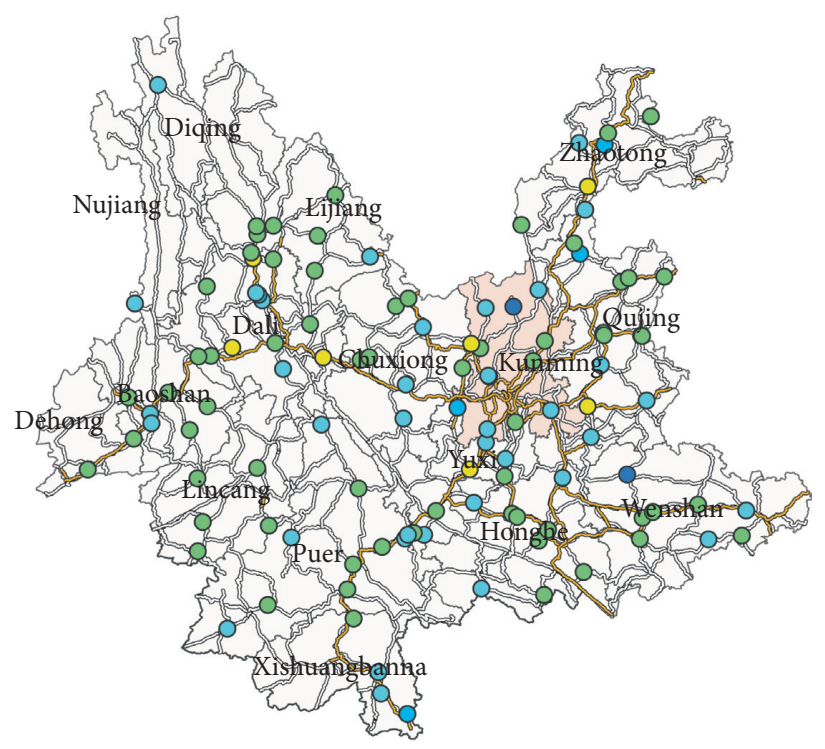

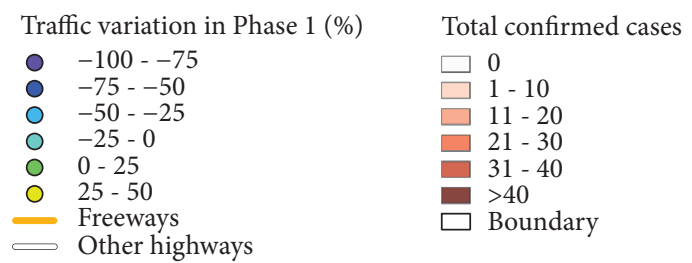

FIgURE 5: Traffic variations in Phase 1. 
capital of Yunnan. Most traffic count stations have shown a slight increase in traffic in the range of 0 to $25 \%$ compared with those in 2019, while some locations have seen a downtrend in traffic, with most decreases ranging from 0 to $25 \%$. In addition, very few locations have experienced a sharp decrease in traffic. Therefore, people's travel was not affected significantly in Phase 1 . The reason might be that most people were not yet aware of the severity of the pandemic and therefore maintained regular travel during this phase.

During the outbreak of pandemic, Phase 2 is considered the lockdown phase. In this phase, traffic volumes changed significantly (Figure 4). The average decreases in traffic for passenger vehicles and trucks are $53.71 \%$ and $58.57 \%$, respectively. As shown in Figure 6, as the outbreak spread to most cities, traffic volumes in nearly all traffic count stations experienced a significant decline, with a decline of more than $50 \%$ in most stations. In Kunming, where the pandemic was most severe, the decline was even more than $75 \%$. In addition to this, although other cities did not have as many confirmed cases as Kunming had, the traffic also dropped dramatically. The reasons for these changes are diverse. On the one hand, the number of new confirmed cases in Hubei Province increased rapidly in this period. Then, the city of Wuhan was declared closed, deepening the people's fear of the pandemic. On the other hand, the Yunnan Province government took a lesson from Wuhan's antipandemic policies and implemented strict control measures, such as No. 1 to No. 6 policies (Table 4), to prevent a surge in cases during this period. The policies led to a significant drop in traffic volume. Moreover, this change continued to the end of Phase 3. In Phase 3, the average decrease in traffic was $59.67 \%$ for passenger vehicles and $68.19 \%$ for trucks (Figure 4). The distribution of traffic variation in Figure 7 also shows a decline across the province. This is due to the recommendation to reduce nonessential travel and the fact that many businesses had not yet resumed.

The province-wide traffic shows overall traffic variations across the province, and it is found that traffic variations vary by region. To show more specific impacts in highway traffic by the pandemic, the study selected 16 locations with the highest AADT in 2019 from 16 regions. Figures 8 and 9 present the traffic volume in the 16 locations on highways (nonfreeway). In the figures, point 0 of the $x$-axis represents the Chinese New Year's Eve; other numbers on the $x$-axis represent the number of days before or after the Chinese New Year's Eve.

It is seen from Figure 8 that the passenger vehicle traffic in 2019 and 2020 fluctuated and remained at similar levels in the same region, except for a larger increase in traffic in Xishuangbanna. It shows a gradual decline in truck traffic in 2019 and 2020 (Figure 9) because freight companies gradually started to take their Spring Festival break and freight business gradually decreased during this phase. It can be also seen that, at the beginning of Phase 2, both passenger vehicle traffic and truck traffic reached their lowest values due to the drop in travel demand. Precisely, points 0 and 1 correspond to the Chinese New Year's Eve and Spring Festival, when most people stayed at home with their families according to
Chinese tradition. Then, there was a surge after the first day of the Spring Festival (point 1 on the $x$-axis). For passenger vehicle traffic in 2019, there is a much higher peak than usual in some regions like Qujing, Yuxi, Baoshan, Lijiang, Xishuangbanna, and Diqing. Then, it fell back to the normal level. The peak may be caused by the increase in travel demand for tourism and visiting relatives. The recovery of traffic is mainly attributed to people returning to the workplace. However, passenger traffic showed a continued downward trend after only a brief and slight rebound after the first day of the Spring Festival (point 1 on the $x$-axis). Many people postponed their plans to return to their workplaces due to the non-opening of businesses and government antipandemic policies, which led to the continuous drop in passenger vehicle traffic. For truck traffic in 2020 (Figure 9), it should have continued to rebound to normal levels from the lows at the beginning of Phase 2 as it did in 2019. However, many freight businesses could not operate normally due to the pandemic, so truck traffic also remained at a low level. In Phase 3, the passenger vehicle traffic (Figure 8) and the truck traffic (Figure 9) remained almost at their lowest levels. It did not go up significantly, even though some companies were already open for business, which indicates that most people still followed that the antipandemic policy of reducing nonessential travel.

Traffic on the freeways has also shown similar results according to six traffic count stations on freeways (Figures 10 and 11). During the first phase, similar to the nonfreeway, passenger vehicle traffic fluctuated at a level or grew slightly. However, at the beginning of the second phase (point 0 or point 1), there was no sudden and pronounced drop as the nonfreeway. Subsequently, instead of a surge in passenger vehicle traffic in 2020 that exceeded the usual level three times as in 2019, it decreased increasingly to the lowest level and maintained at the lowest level until the end of Phase 3. For truck traffic, freeway traffic and nonfreeway traffic are similar.

\subsubsection{Impacts on Intercity Public Transportation.} Highways connect the cities. The intercity bus is an importation travel mode for long-distance trips from one city to another. The intercity bus traffic trends at the 16 locations are presented in Figure 12. Although the intercity bus traffic only accounts for less than $10 \%$ of passenger vehicle traffic, it is seen from Figure 12 that the intercity bus traffic had been severely impacted. In the three phases of Period I, as shown in Figure 12, the trend of intercity bus traffic is similar to that of passenger traffic mentioned above. To better understand the variation of intercity bus traffic, the variation and bus usage in each phase in all locations are presented in Table 5.

In Phase 1, the intercity bus traffic did not change significantly. Some locations experienced a slight drop in intercity bus traffic, such as Kunming, Zhaotong, Dehong, Nujiang, and Diqing. The drops range from $-5.5 \%$ to $-27.5 \%$. In comparison, some locations experienced a dramatic increase in intercity bus traffic, like Xishuangbanna, Wenshan, and Dali, whose increase rates are $111 \%$, $310 \%$, and $425.5 \%$, respectively. The proportion of intercity 


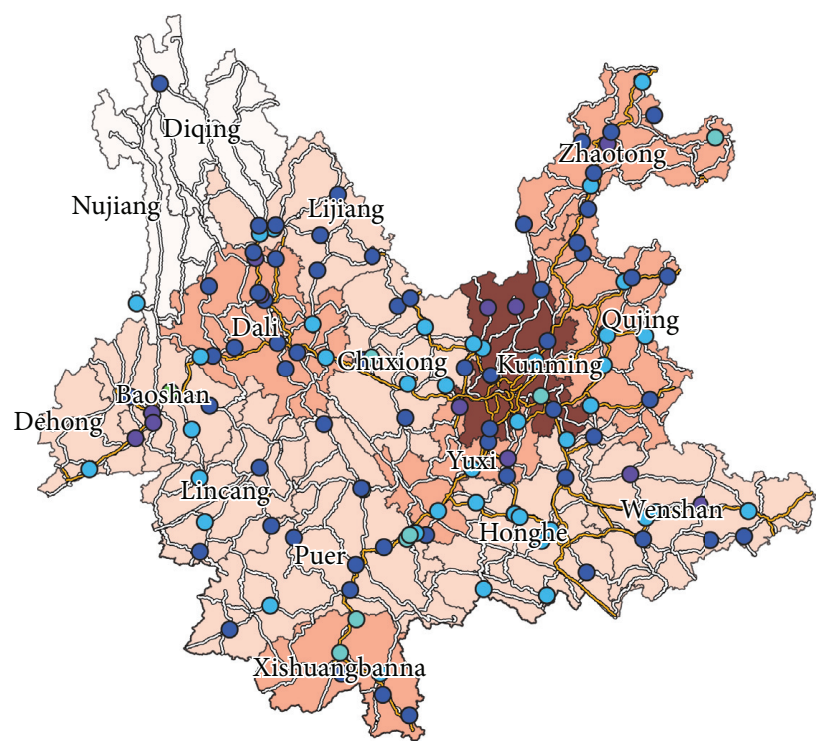

$\begin{array}{ll}\text { Traffic variation in Phase 2 (\%) } & \text { Total confirmed cases } \\ \circ-100--75 & \square 0 \\ \bigcirc-75--50 & \square 1-10 \\ \bigcirc-50--25 & 11-20 \\ \bigcirc-25-0 & 21-30 \\ \bigcirc \quad 0-25 & 31-40 \\ \bigcirc \quad 25-50 & \square \text { Boundary } \\ \rightleftharpoons \text { Freeways } & \text { Other highways }\end{array}$

Figure 6: Traffic variations in Phase 2.

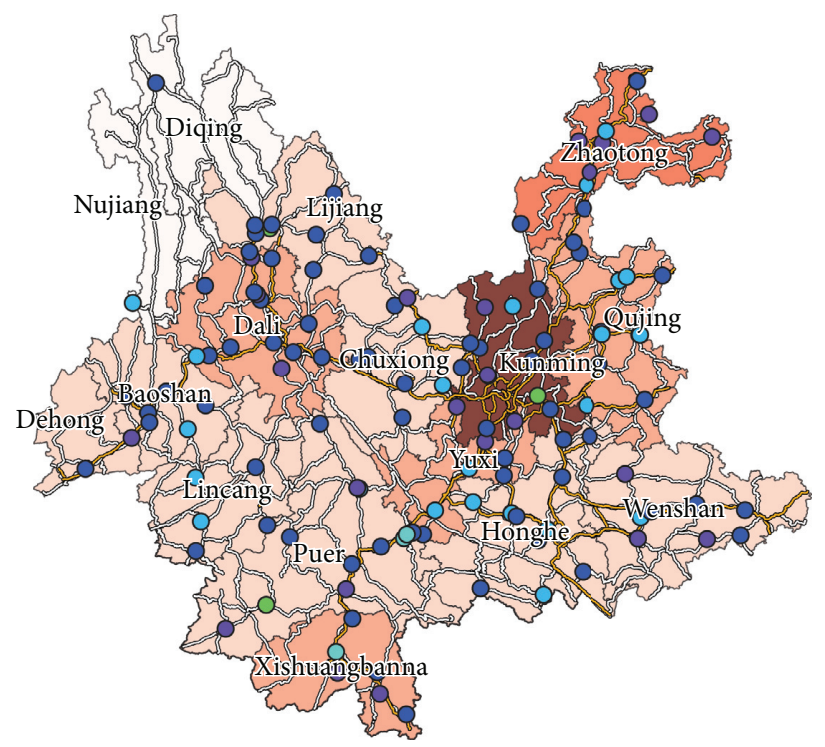

$\begin{array}{ll}\text { Traffic variation in Phase 3 (\%) } & \text { Total confirme } \\ \circ-100-75 & \square 0 \\ \circ-75--50 & \square 1-10 \\ \circ-50--25 & \square 11-20 \\ \circ-25-0 & 21-30 \\ \circ \quad 0-25 & 31-40 \\ \bigcirc \quad 25-50 & \square \text { Boundary } \\ \square \text { Freeways } & \end{array}$

Figure 7: Traffic variation in Phase 3. 

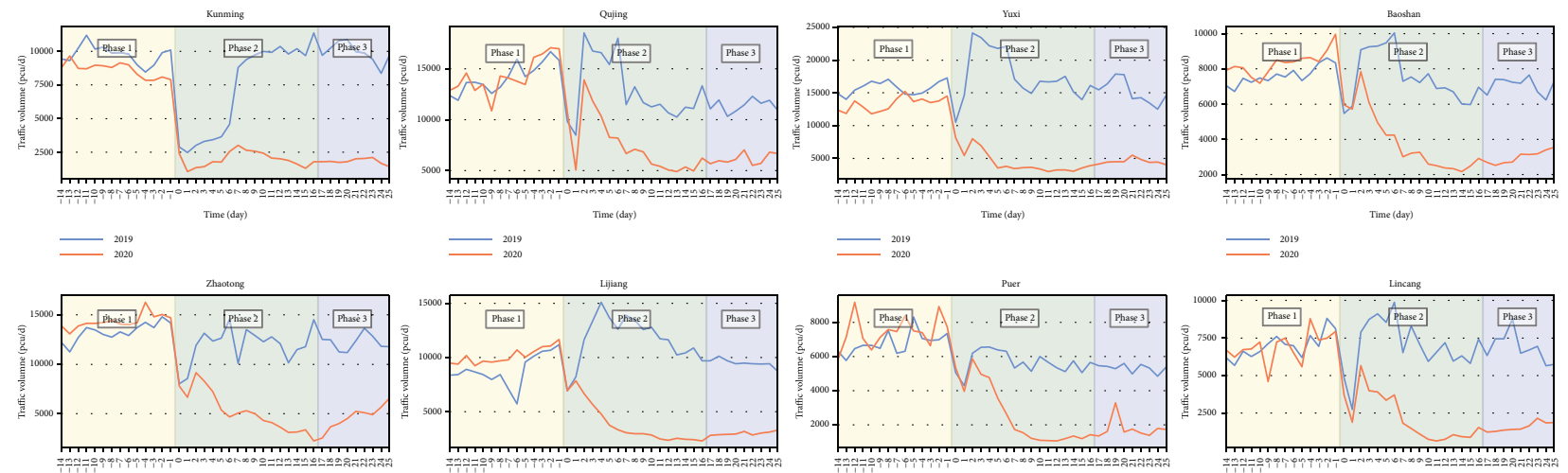

$-{ }^{2019}$

2019
-2020

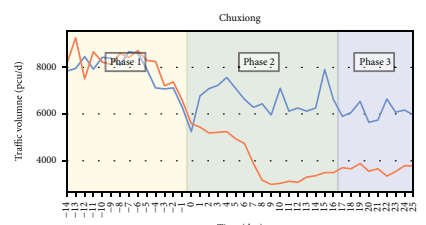

- 2019

$\square_{2000}^{2019}$
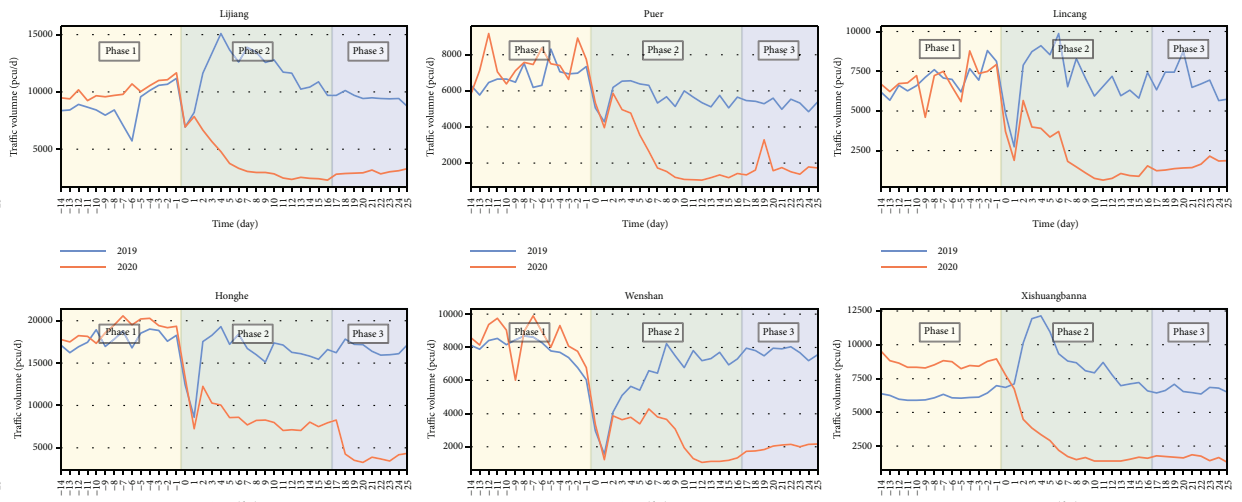

2019
-220

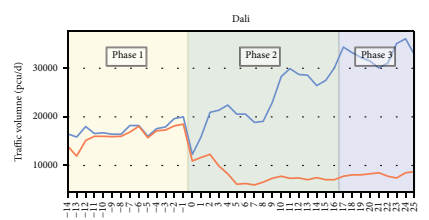

2019
2020

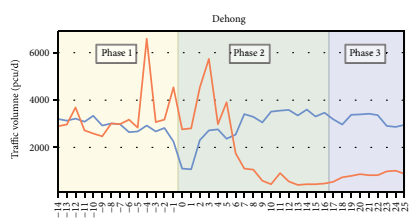

${ }^{2019}$

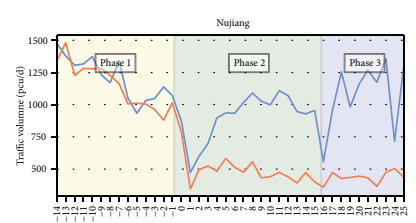

— 2019

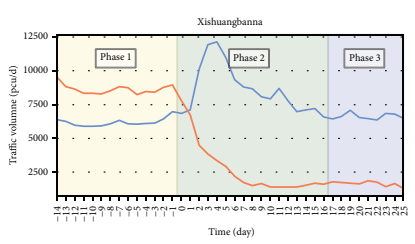

2019
$-\quad 2020$

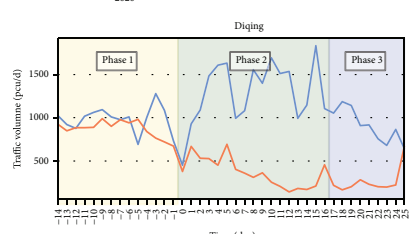

三

$\square \quad{ }^{2019}$

${ }^{2019}$

${ }^{2019}$

Figure 8: Traffic volume of passenger vehicles on highways.
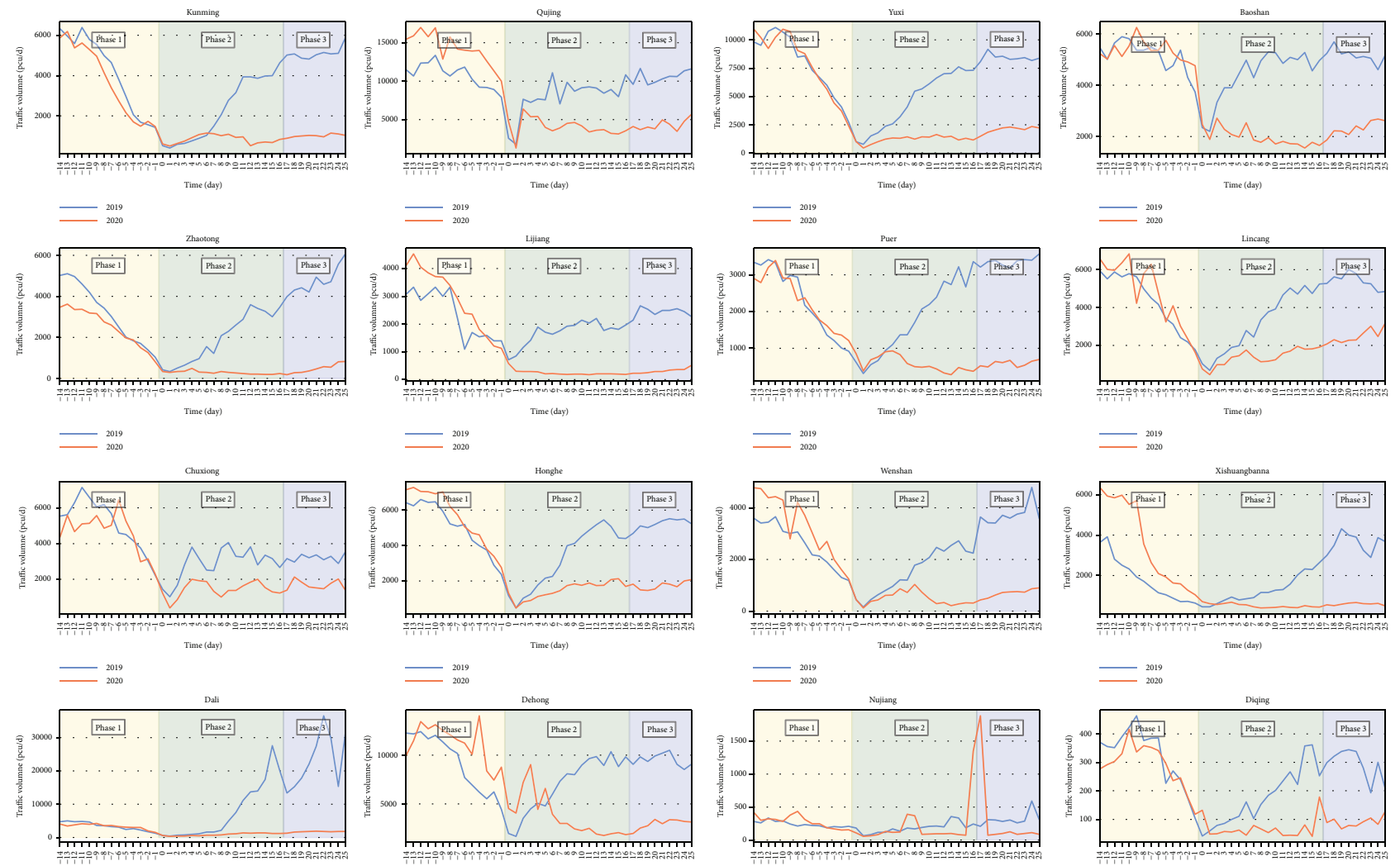

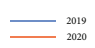

${ }_{2019}^{2019}$

$\bar{Z}_{2019}^{2019}$

Figure 9: Traffic volume of trucks on highways. 

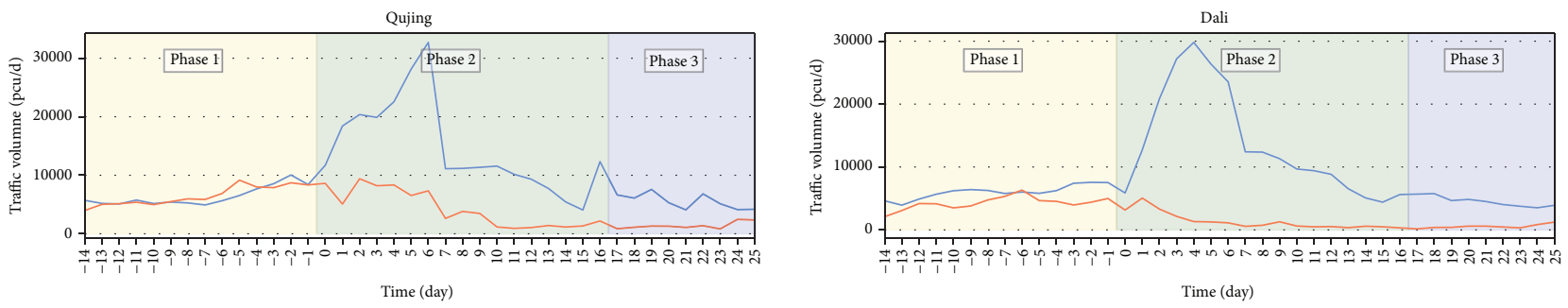

二 2019

Kunming
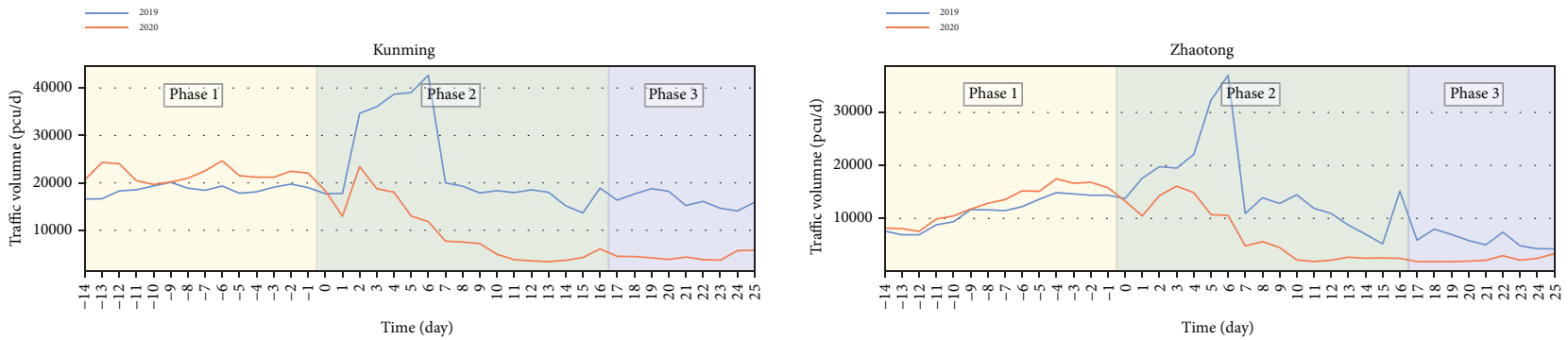

${ }^{2020}$

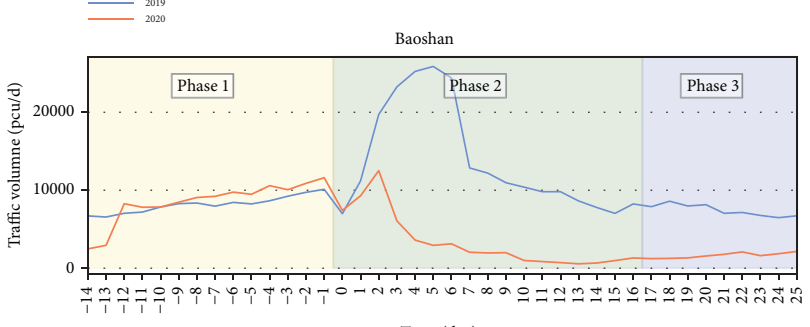

Time (day)
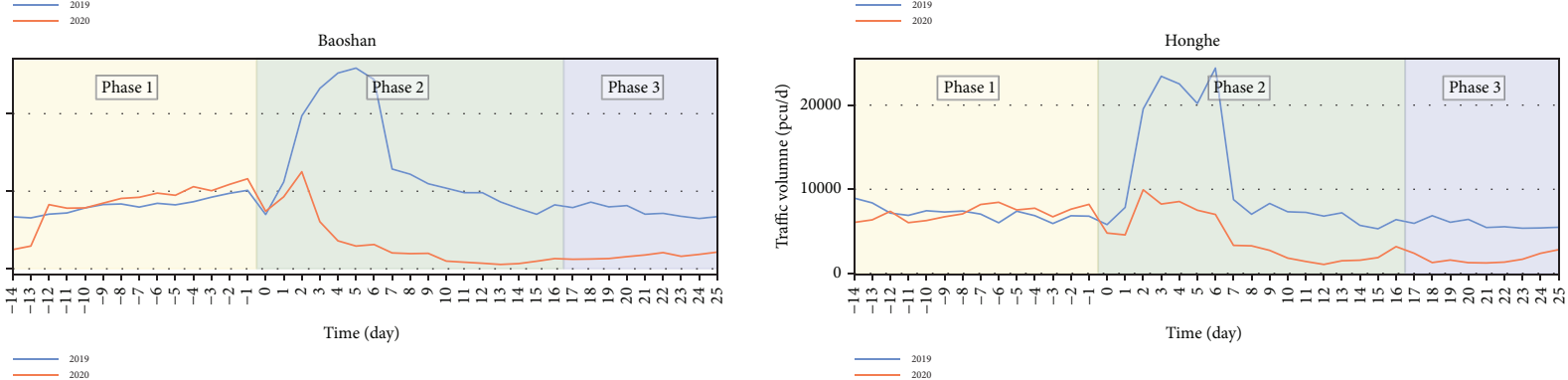

$\overline{ }^{2019}$

Figure 10: Traffic volume of passenger vehicles on freeways.
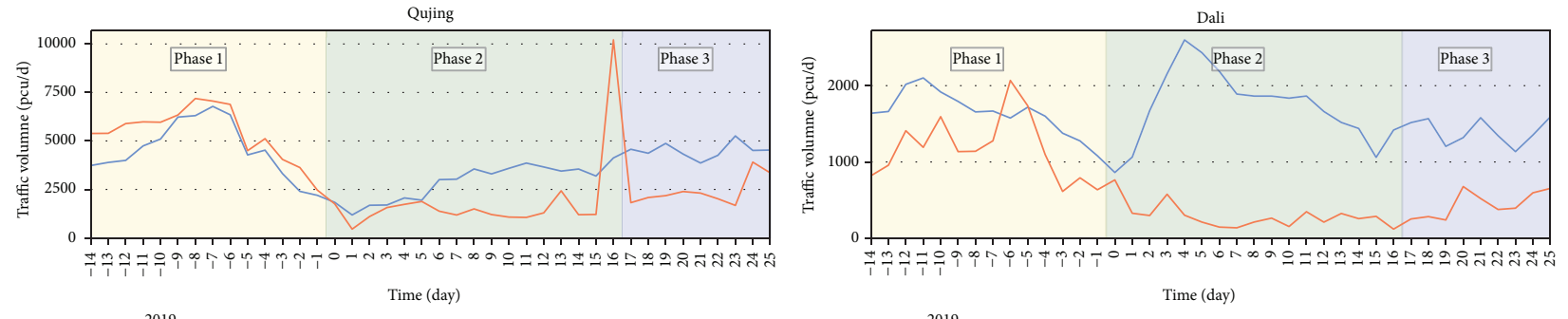

-2019
-2020

-2019
-2020
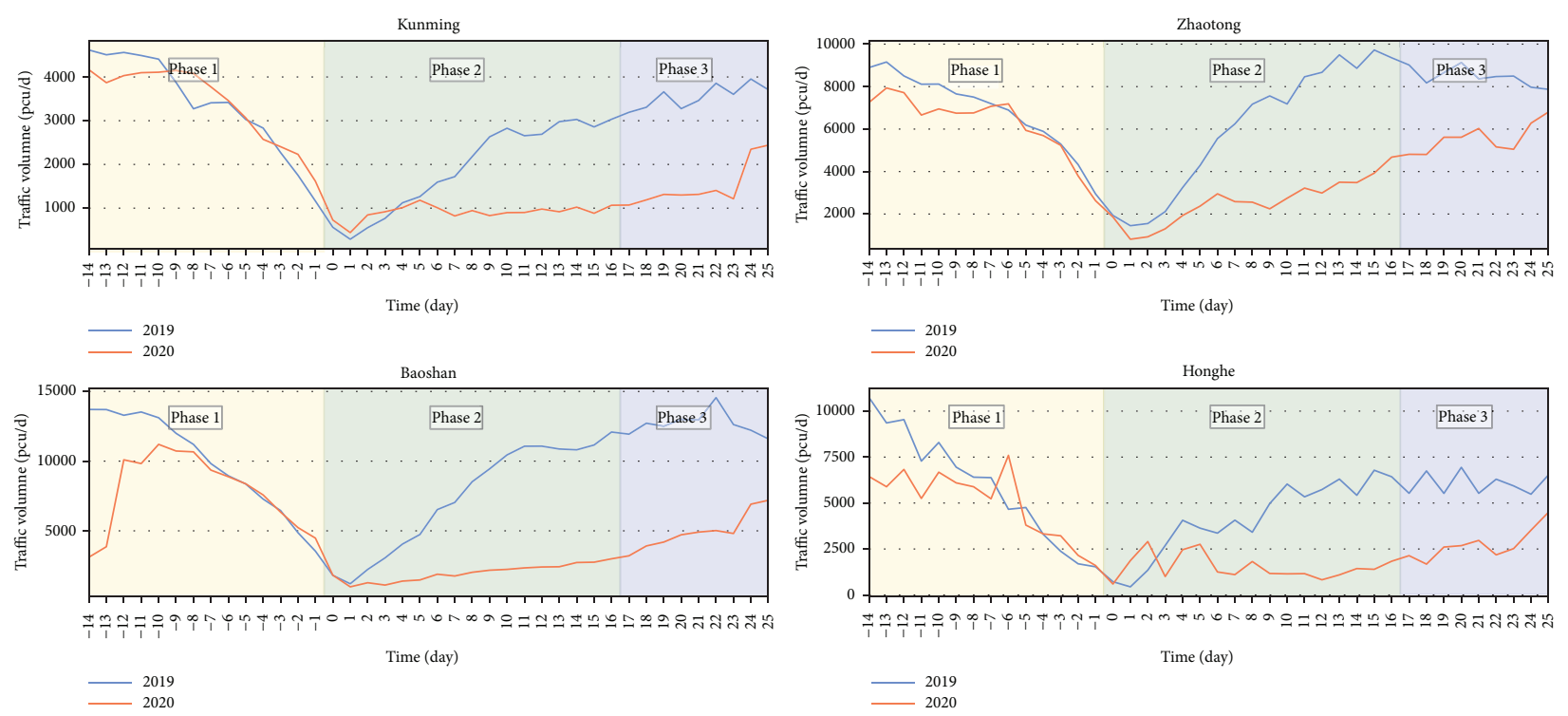

Figure 11: Traffic volume of trucks on freeways. 

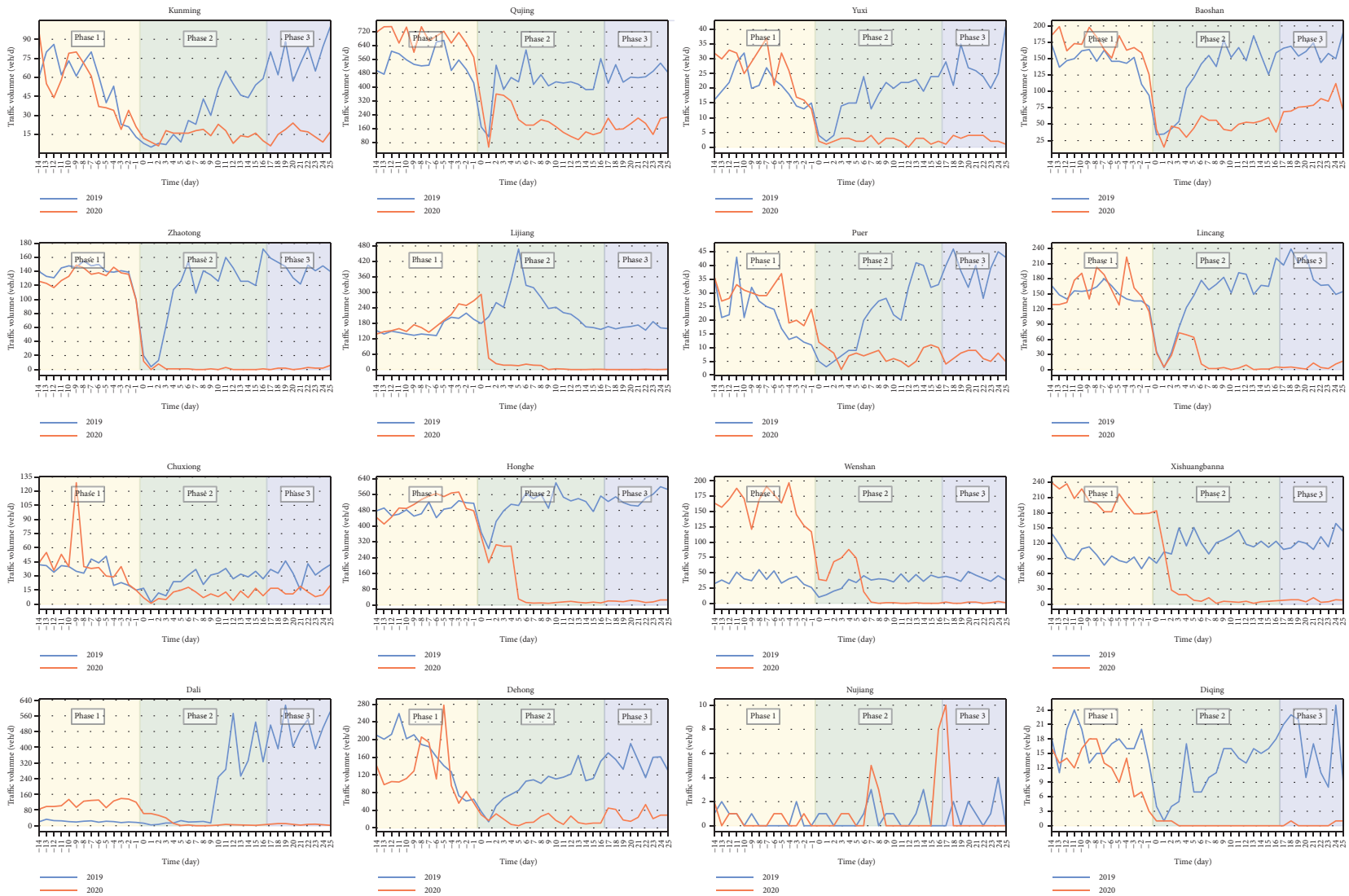

${ }_{20100}^{2019}$

Figure 12: Traffic volume trends of intercity bus traffic on highways.

Table 5: Traffic variations of the intercity bus in three phases.

\begin{tabular}{|c|c|c|c|c|c|c|c|c|c|}
\hline \multirow[t]{2}{*}{ Regions } & \multicolumn{3}{|c|}{ Traffic variation of the intercity bus (\%) } & \multicolumn{2}{|c|}{$\begin{array}{l}\text { Proportion in } \\
\text { phase } 1(\%)\end{array}$} & \multicolumn{2}{|c|}{$\begin{array}{l}\text { Proportion in } \\
\text { phase } 2(\%)\end{array}$} & \multicolumn{2}{|c|}{$\begin{array}{l}\text { Proportion in } \\
\text { phase } 3(\%)\end{array}$} \\
\hline & Phase 1 & Phase 2 & Phase 3 & 2019 & 2020 & 2019 & 2020 & 2019 & 2020 \\
\hline Kunming & -7.6 & -55.1 & -80.0 & 0.6 & 0.6 & 0.4 & 0.7 & 0.8 & 0.8 \\
\hline Qujing & 26.6 & -52.7 & -59.8 & 3.9 & 4.9 & 3.3 & 2.7 & 4.3 & 3.2 \\
\hline Yuxi & 29.7 & -87.0 & -89.9 & 0.1 & 0.2 & 0.1 & 0.05 & 0.2 & 0.1 \\
\hline Baoshan & 17.5 & -62.5 & -50.4 & 1.9 & 2.1 & 1.7 & 1.2 & 2.3 & 2.7 \\
\hline Zhaotong & -5.5 & -98.4 & -98.6 & 1.1 & 0.9 & 0.9 & 0.0 & 1.2 & 0.0 \\
\hline Lijiang & 13.6 & -88.9 & -99.9 & 1.8 & 1.8 & 2.1 & 0.7 & 1.8 & 0.0 \\
\hline Puer & 23.9 & -64.7 & -82.9 & 0.3 & 0.4 & 0.4 & 0.3 & 0.7 & 0.4 \\
\hline Lincang & 4.9 & -86.8 & -96.5 & 2.2 & 2.3 & 2.0 & 0.8 & 2.8 & 0.4 \\
\hline Chuxiong & 25.1 & -60.8 & -60.3 & 0.4 & 0.5 & 0.4 & 0.2 & 0.6 & 0.4 \\
\hline Honghe & 4.7 & -80.8 & -96.2 & 2.8 & 2.7 & 3.2 & 1.1 & 3.3 & 0.5 \\
\hline Wenshan & 310.0 & -31.8 & -97.1 & 0.5 & 1.9 & 0.6 & 0.9 & 0.5 & 0.1 \\
\hline Xishuangbanna & 111.0 & -78.9 & -93.7 & 1.6 & 2.4 & 1.4 & 0.9 & 1.9 & 0.5 \\
\hline Dali & 425.5 & -90.2 & -98.6 & 0.1 & 0.7 & 0.7 & 0.2 & 1.5 & 0.1 \\
\hline Dehong & -22.9 & -82.3 & -79.8 & 5.8 & 3.9 & 3.4 & 0.9 & 4.9 & 3.7 \\
\hline Nujiang & -12.5 & 50.0 & 0.0 & 0.05 & 0.04 & 0.1 & 0.2 & 0.1 & 0.2 \\
\hline Diqing & -27.5 & -98.4 & -97.9 & 1.7 & 1.4 & 0.9 & 0.0 & 1.8 & 0.1 \\
\hline
\end{tabular}

buses in passenger vehicle traffic in different regions is low, ranging from $0.05 \%$ to $5.8 \%$ in 2019 and $0.04 \%$ to $4.9 \%$ in 2020. Compared with its proportion of $1.6 \%$ in 2019 , the intercity bus proportion is $1.7 \%$ in 2020 , which means a slight rise of $6.3 \%$ in intercity bus usage. Therefore, in this phase, intercity bus usage did not change significantly. However, in Phase 2, the intercity bus traffic in most locations suffered a drop ranging from $31.8 \%$ to $98.4 \%$. Also, compared with its value of $1.3 \%$ in 2019 , the intercity bus proportion was $0.8 \%$ in 2020 , which means a drop of $38.5 \%$ in intercity bus usage. In Phase 3, the intercity bus traffic still decreased significantly, with a drop ranging from $59.8 \%$ to 98.6\%. Meanwhile, the average proportion decreased from $1.8 \%$ to $0.8 \%$ in this phase, which dropped by $55.6 \%$ in 
intercity bus usage. Therefore, the intercity bus traffic decreased in both volume and usage, which indicates that people used public transportation less. More precisely, the travel demand decreased, and fewer people used the intercity bus due to the pandemic.

5.2. Impacts on Traffic in Different Regions. The impacts of COVID-19 on the transportation industry also affect economic development. There typically exists some relationship between transportation and economic development [39]. To analyze the impacts of the pandemic on traffic in different regions, a K-means cluster analysis based on the attributes of regions was conducted. Five indicators were selected to perform the K-means cluster, including per capita GDP, GDP growth rate, the total number of confirmed cases, reduction in passenger vehicle traffic, and reduction in truck traffic. The data used for clustering are for the first quarter of 2020, as shown in Table 3. The per capita GDP and GDP growth rate describe the level of economic development. Total confirmed cases reflected the severity of the pandemic. In addition, reductions in passenger vehicle traffic and truck traffic reflected the extent to which traffic was affected, which were calculated using equation (3). Then, using cluster analysis, the regions were divided into four categories: Level A, Level B, Level C, and Level D, as presented in Table 6 and Figure 13.

Level A category contained only one region, Kunming, the capital of Yunnan Province. The most distinctive feature of this category is the highest per capita GDP, at 22091.5 CNY, far exceeding other categories. The number of confirmed cases was also the largest. In addition, passenger vehicle traffic and truck traffic both received a significant impact, with $28.9 \%$ and $35.1 \%$ decreases, respectively. However, its economy had not been greatly affected, with only a $5.6 \%$ fall in its GDP.

Level B category includes five regions. Compared with the Level A category, per capita GDP was much less in Level $\mathrm{B}$, at $1,2648.6 \mathrm{CNY}$. The average number of confirmed cases in this category was about 6.4, the lowest in all categories. However, the traffic in these regions suffered the greatest impact; passenger vehicle traffic and truck traffic fell by $33.3 \%$ and $35.4 \%$, respectively. The economic impact in these regions was minimal, with a $1.5 \%$ fall in GDP.

Compared with the first two categories, the per capita GDP of Level C was at a relatively low level, at 7712.2 CNY. The average number of confirmed cases was 8.2 ; and passenger vehicle traffic and truck traffic did not drop as much as Level A and Level B, only $25.7 \%$ and $27.5 \%$, respectively. However, its economy was indeed the most affected, with an $11.8 \%$ fall in GDP.

The level of economic development of Level D was the lowest, with a per capita GDP of only 6967.1 CNY. The average number of confirmed cases was at a low level, at 9.6. Also, the impact of the pandemic on traffic was the lowest among all categories, with traffic falling by only $17.8 \%$ for passenger vehicle traffic and $12.3 \%$ for truck traffic. The impact of the pandemic on the economy was also relatively low, only dropping by $1.9 \%$ in GDP.
Comparing Levels B, C, and D, it can be found that under a similar level of confirmed cases, the lower the level of economic development in the region was, the less traffic was affected. However, Level A was a particular case because Level A only contains only one city, the capital Kunming. Although its number of confirmed cases was much larger than that of other categories, passenger vehicle traffic and truck traffic declined slightly lower than Level B due to its role as a regional transportation hub.

\subsection{Traffic Recovery}

5.3.1. Recovery of Province-Wide Traffic. Although the pandemic was contained in the first quarter of 2020, traffic volume across the province remained impacted for a long time due to the regular antipandemic policies (e.g., temperature testing required to enter public transportation or public places and health code compliance).

From a full-year perspective, the comparison of the annual average daily traffic (AADT) between 2019 and 2020 is shown in Figure 14. The average AADT of passenger vehicles of all traffic count stations decreased by approximately 6\%, from 4,266 pcu/d in 2019 to $4,010 \mathrm{pcu} / \mathrm{d}$ in 2020 . The average AADT of trucks of all traffic count stations decreased by about $3 \%$ to $2,921 \mathrm{pcu} / \mathrm{d}$ in 2020 from $3,005 \mathrm{pcu} / \mathrm{d}$ in 2019. Moreover, the median AADT for passenger vehicles fell $16 \%$ from $3455 \mathrm{pcu} / \mathrm{d}$ to $2898 \mathrm{pcu} / \mathrm{d}$, while the median AADT for trucks rose $2 \%$ from $2431 \mathrm{pcu} / \mathrm{d}$ to $2469 \mathrm{pcu} / \mathrm{d}$.

To show the recovery tendency of the traffic volume in 2020, the daily traffic volume in 2020 was compared with that in 2019. The comparison results are shown in Figures 15 and 16. The variation is calculated using equation (4).

The whole process of traffic recovery is evident (Figure 15). Before January $23^{\text {rd }}$ of 2020 , it was clear that the average traffic variation of all traffic count stations was higher than the AADT of 2019. Later, traffic variation declined to its lowest point of the year in early February under the impact of the pandemic. Then, traffic variation began to recover. In late February, traffic variation had recovered to around $80 \%$ of the AADT for 2019 . Traffic variation finally recovered to the AADT level of 2019 at the end of April. Then, from May to December, average traffic volumes fluctuated around the AADT level of 2019. In addition, the recovery of truck traffic is better than that of passenger vehicles (Figure 16). The average variation for trucks is above the AADT of 2019 after March $2^{\text {nd }}$. Therefore, the pandemic had a longer impact on passenger vehicles than on trucks.

Based on the trend of passenger vehicle traffic variation throughout the year, the entire recovery process can be divided into four stages as shown in Table 7 . The first is the "Decline Stage," ranging from January $23^{\text {rd }}$ to February $6^{\text {th }}$. The traffic declined significantly in this stage. The second stage is the "Rapid Recovery Stage," starting from February $7^{\text {th }}$ to February $24^{\text {th }}$, in which traffic recovered rapidly within about 18 days. Thirdly, from February $25^{\text {th }}$ to April $30^{\text {th }}$, it is the "Slow Recovery Stage," lasting about 66 days. Although the pandemic was under control in this period, the recovery 
TABLE 6: K-means cluster analysis result.

\begin{tabular}{lcccccc}
\hline Categories & $\begin{array}{c}\text { Per capita GDP } \\
\text { (CNY) }\end{array}$ & $\begin{array}{c}\text { Growth rate of } \\
\text { GDP (\%) }\end{array}$ & $\begin{array}{c}\text { Reduction in passenger } \\
\text { vehicle traffic (\%) }\end{array}$ & $\begin{array}{c}\text { Reduction in truck } \\
\text { traffic (\%) }\end{array}$ & $\begin{array}{c}\text { Total confirmed } \\
\text { cases }\end{array}$ & $\begin{array}{c}\text { Number of } \\
\text { cities }\end{array}$ \\
\hline Level A & 22091.5 & -5.6 & -28.9 & -35.1 & 60 & 1 \\
Level B & 12648.6 & -1.5 & -33.3 & -35.4 & 6.4 \\
Level C & 7712.2 & -11.8 & -25.7 & -27.5 & 5.2 \\
Level D & 6967.1 & -1.9 & -17.8 & -12.3 & 5 \\
\hline
\end{tabular}

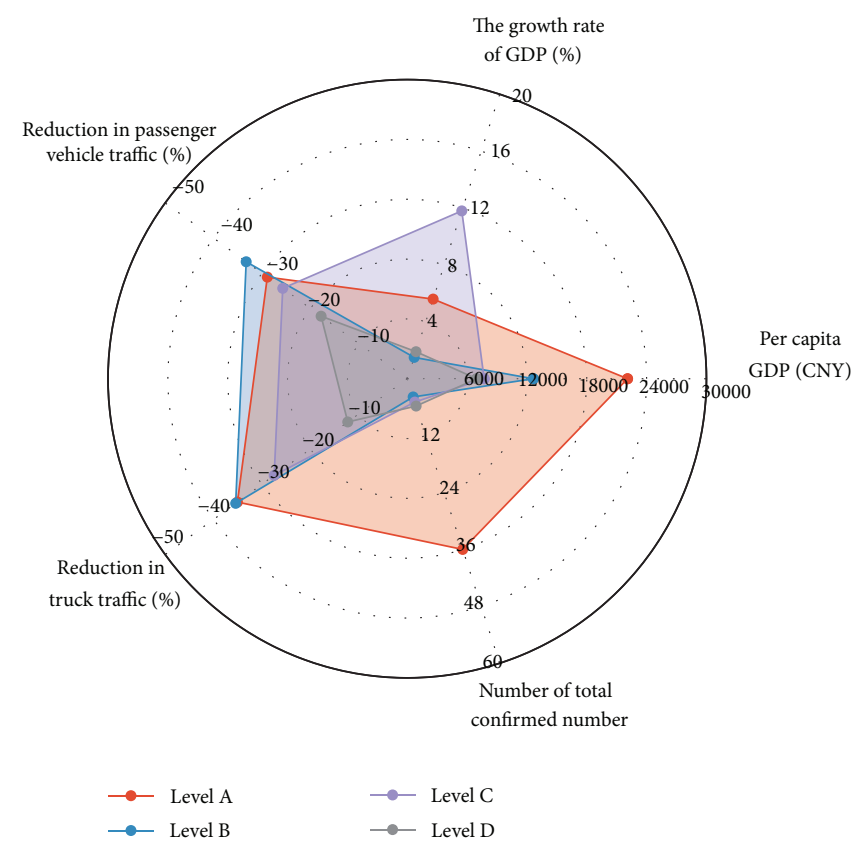

FIgURE 13: Traffic and economic characteristics of four types of regions under the impact of the pandemic.

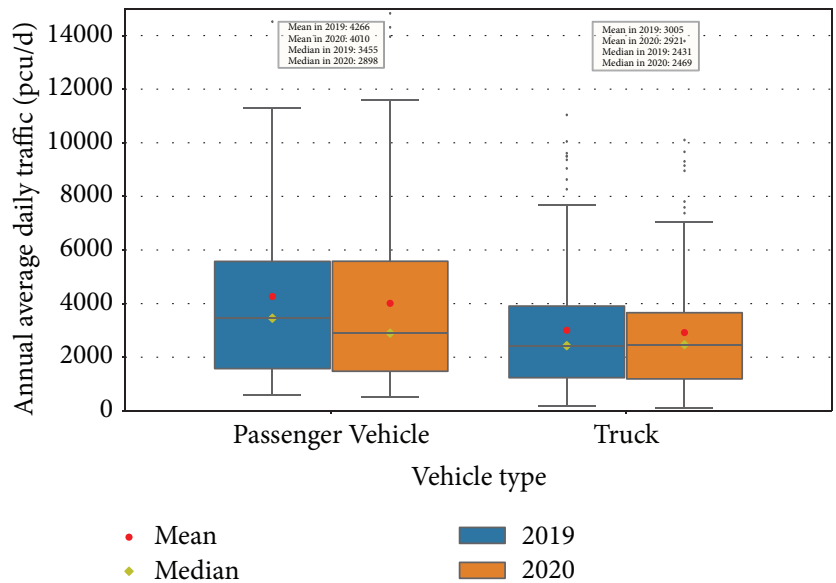

FIgURE 14: Comparison of annual average daily traffic between 2019 and 2020.

of traffic volume slowed down. Finally, the stage after May $1^{\text {st }}$ is the "Normal Stage." During this period, traffic volumes fully recovered to prepandemic levels.

For truck traffic, the recovery process can be divided into only three stages: "Decline Stage," "Rapid Recover Stage," and "Normal Stage." The Decline Stage, from January $12^{\text {th }}$ to January $25^{\text {th }}$, lasted for 14 days. Compared with passenger vehicle traffic, the truck traffic only suffered a Rapid Recover Stage from January $26^{\text {st }}$ to March $2^{\text {th }}$, about 37 days. Since March $3^{\text {rd }}$, the truck traffic backed to normal.

The recovery rate of passenger vehicle traffic varies greatly during the rapid recovery period and the slow recovery period. During the Rapid Recovery Stage, it took 18 days for passenger vehicles to recover from $-60 \%$ to $-20 \%$, with an average 


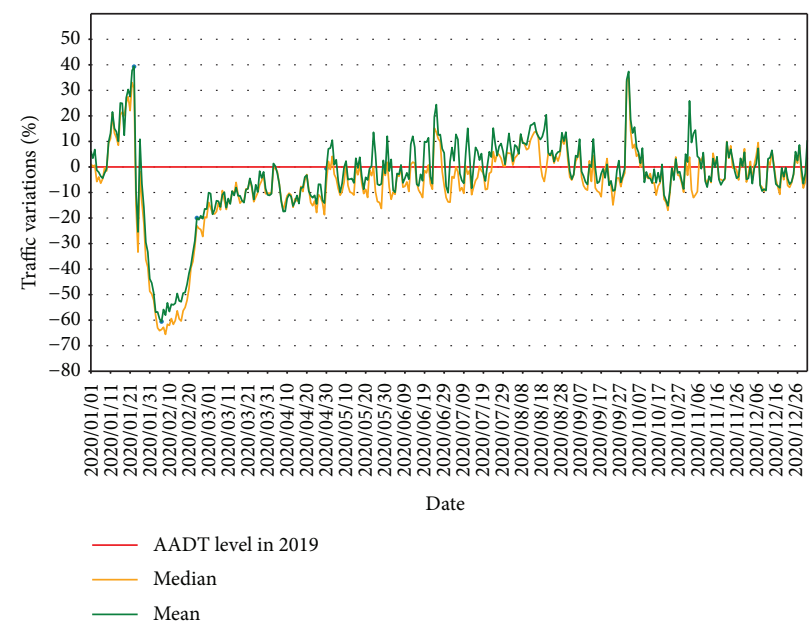

FIGURE 15: Daily traffic variations of passenger vehicles during 2020.

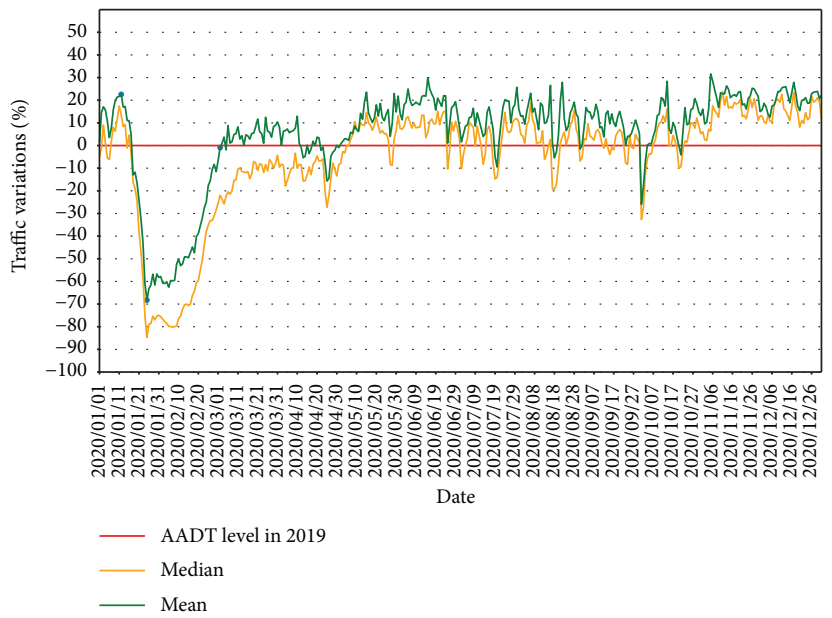

Figure 16: Daily traffic variations of trucks during 2020.

recovery rate of $15.6 \%$ per week. In contrast, during the Slow Recovery Stage, it took 66 days to recover from $-20 \%$ to the 2019 AADT level, with a recovery rate of about $2.1 \%$ per week. The recovery rate of truck traffic is $12.9 \%$ per week on average.

To better present the traffic recovery process, the changes in traffic volume for each quarter of 2020 were calculated compared with those in the corresponding quarter of 2019 based on equation (3). The results are shown in Figure 17.

The results were analyzed using hypothesis testing. According to the assumptions shown in equations (7) and (8), Table 8 presents the results of hypothesis testing. The results confirmed that the average traffic volume in the first quarter of 2020 was significantly lower than the traffic volume in 2019. The traffic volumes in the second, third, and fourth quarters were significantly greater than or equal to those in the same period of 2019. In other words, traffic volumes had recovered in the second quarter of 2020.

5.3.2. Recovery of Passenger and Freight Transportation. The impact of the pandemic on highway passenger and freight transportation lasted for a whole year in 2020. The annual highway passenger-kilometer (pkm) in Yunnan Province in 2020 was 13.85 billion pkm, and highway tonnekilometer of freight was 110.15 billion ton-km [32]. Compared with the numbers in 2019 , they decreased by $44.9 \%$ and $32.9 \%$, respectively.

The impacts include not only a reduction in volume but also a reduction in the proportion of highway transportation relative to other modes of transportation. Figure 18 shows the highway passenger-kilometers and tonne-kilometers in 2020. It is seen that the proportion of highway passengerkilometers experienced a general downward trend from 2018 to 2020 . The proportion dropped from $46 \%$ in 2018 to $39 \%$ in 2019 and finally to $38 \%$ in 2020 (Figure 18(a)). It is worth noting that more people chose to travel by private car due to the pandemic in 2020, especially in the first half of the year. In addition, the cancellation of a large number of trains and flights in the first quarter of 2020 also led to an increase in road passenger traffic. Therefore, the proportion of highway passenger traffic in the first half of 2020 is higher than that in 2019. In contrast, the proportions of tonne-kilometers of freight in 2018 and 2019 were both $76 \%$ but the number dropped to $71 \%$ in 2020 (Figure 18(b)). 
TABLE 7: Stages in the traffic recovery process.

\begin{tabular}{lcccc}
\hline Vehicle type & Stage & Time range (2020) & Duration & Characteristics \\
\hline \multirow{4}{*}{ Passenger vehicle } & Decline stage & Jan. 23 to Feb. 6 & 15 days & Traffic decreased dramatically \\
& Rapid recovery stage & Feb. 7 to Feb. 24 & 18 days & Traffic recovered rapidly \\
& Slow recovery stage & Feb. 25 to Apr.30 & 66 days & Traffic recovered slowly \\
& Normal stage & May 1 to Dec.31 & - & Traffic fluctuated and increased slightly \\
Truck & Decline stage & Jan. 12 to Jan. 25 & 14 days & Traffic decreased dramatically \\
& Rapid recovery stage & Jan. 26 to Mar. 2 & 37 days & Traffic recovered rapidly \\
& Normal stage & Mar. 3 to Dec.31 & - & Traffic fluctuated and increased slightly \\
\hline
\end{tabular}

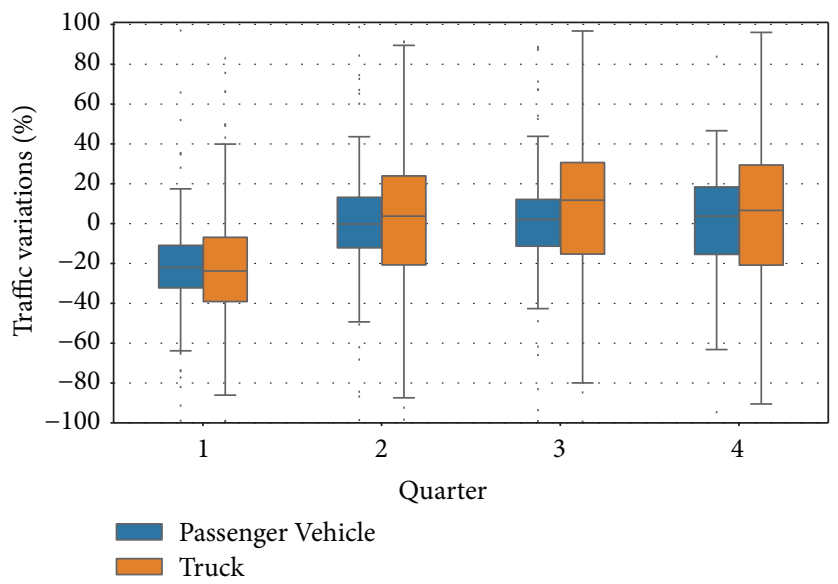

Figure 17: Traffic variations in each quarter compared with 2019 traffic.

TABLE 8: Results of hypothesis testing.

\begin{tabular}{|c|c|c|c|c|}
\hline Vehicle type & Quarter & $\mathrm{t}$ & $p$ value & Result \\
\hline \multirow{4}{*}{ Passenger vehicle } & 1 & -16.98 & 0 & Reject $\mathrm{H}_{0}$ \\
\hline & 2 & -1.32 & 0.09 & Accept $\mathrm{H}_{0}$ \\
\hline & 3 & -0.48 & 0.31 & Accept $\mathrm{H}_{0}$ \\
\hline & 4 & -0.17 & 0.43 & Accept $\mathrm{H}_{0}$ \\
\hline \multirow{4}{*}{ Truck } & 1 & -12.58 & 0 & Reject $\mathrm{H}_{0}$ \\
\hline & 2 & -0.64 & 0.26 & Accept $\mathrm{H}_{0}$ \\
\hline & 3 & 1.88 & 0.03 & Accept $\mathrm{H}_{0}$ \\
\hline & 4 & 0.42 & 0.33 & Accept $\mathrm{H}_{0}$ \\
\hline
\end{tabular}

According to the statistics of Yunnan Province, the freight volume dropped from 1.451 billion tons in 2019 to 1.156 billion tons in 2020 , with a decrease in $20.3 \%$. Passenger-kilometers dropped from 0.307 billion in 2019 to 0.192 billion in 2020, with a decrease in 37.5\% [32]. Figures 18(c) and 18(d) demonstrate the quantities of freight and passenger transportation. It can be seen that despite the recovery of traffic volumes, neither passenger-kilometers nor tonne-kilometers of freight in 2020 reached the same level as in 2019.

\section{Discussion and Policy Implications}

6.1. Impacts of Antipandemic Policies on Traffic. The outbreak of COVID-19 had a profound impact on many industries [40], especially transportation. Previous sections have provided a comprehensive demonstration of the impacts of COVID-19 on highway traffic. To better understand the impacts of pandemic and antipandemic policies, the main findings from the previous section are summarized in Table 9.

Apparently, at the beginning of the pandemic (Phase 1), there was no official antipandemic policy. Therefore, traffic was not affected. However, in Phase 2, the overall traffic dropped by $53.71 \%$ for passenger vehicles and $58.57 \%$ for trucks, respectively. Such a significant drop in traffic occurred mainly due to the strict antipandemic policies of the Yunnan government. For example, with the surge in the number of confirmed cases, the government adopted strict antipandemic policies No.1-No.6 in Table 4. These strict policies appeared to be effective as the number of new confirmed cases decreased to 14 in Phase 3.

In addition, there was a general reduction in traffic in Phase 2 and Phase 3 throughout the province, regardless of whether the number of confirmed cases in the region was high or low, as presented in Figures 5-7 in Section 4. The 


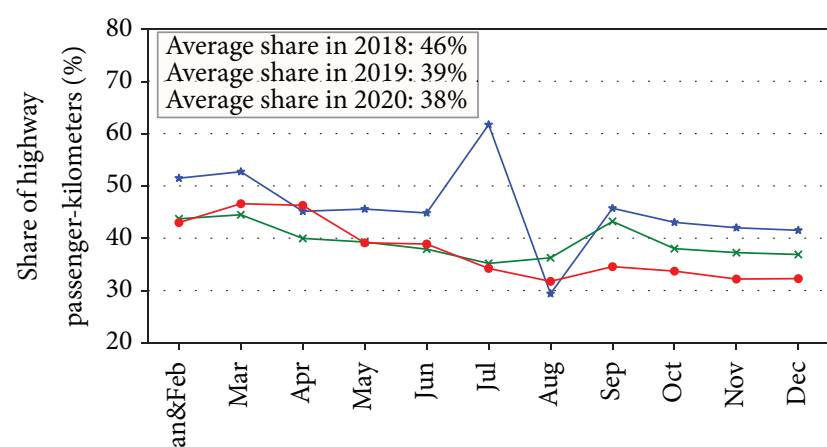

Month

$$
\begin{aligned}
& \rightarrow-2018 \\
& -2019 \\
& \rightarrow-2020
\end{aligned}
$$

(a)

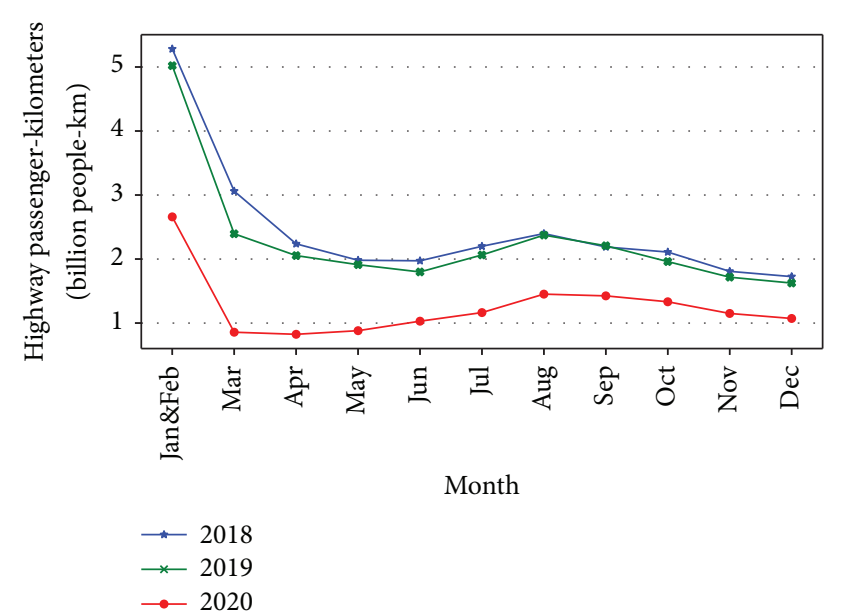

(c)

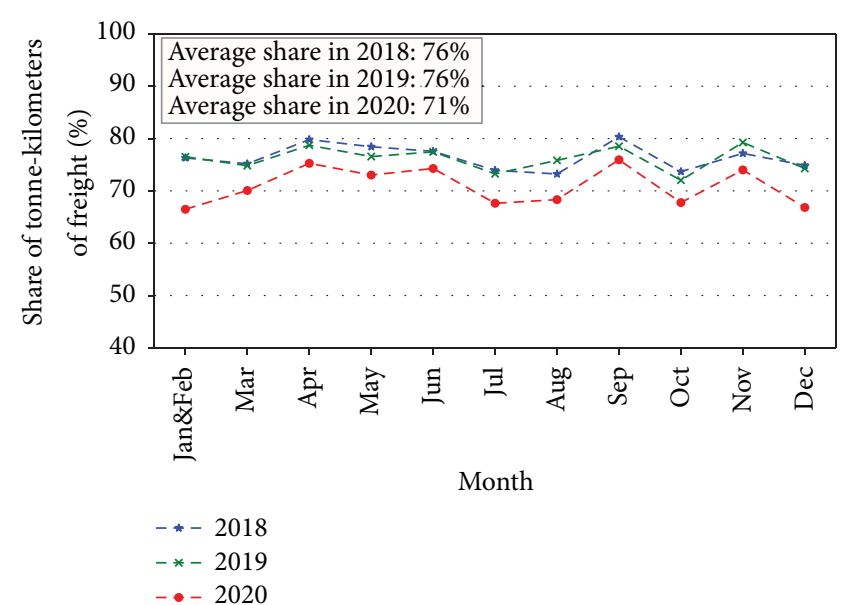

(b)

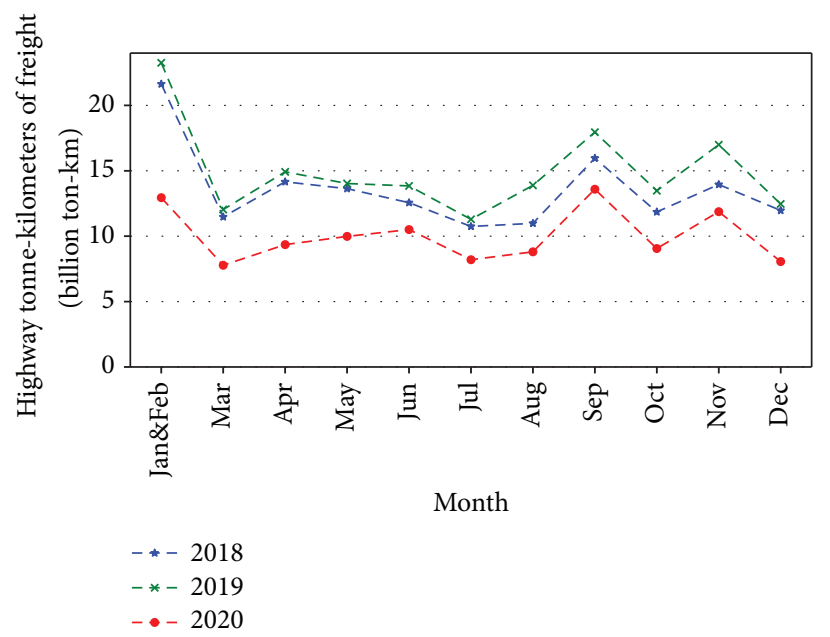

(d)

FIGURE 18: Highway passenger and freight transportation. (a) Share of highway passenger-kilometers. (b) Share of highway tonne-kilometers of freight. (c) Highway passenger-kilometers. (d) Highway tonne-kilometers of freight.

\begin{tabular}{|c|c|c|c|c|c|}
\hline Phase & Date (2020) & $\begin{array}{c}\text { \# of new confirmed } \\
\text { cases }\end{array}$ & Policy number & $\begin{array}{c}\text { Variation in passenger vehicle } \\
\text { traffic (\%) }\end{array}$ & $\begin{array}{l}\text { Variation in truck } \\
\text { traffic }(\%)\end{array}$ \\
\hline 1 & $\begin{array}{c}\text { Jan. } 10 \text { to Jan. } \\
23\end{array}$ & 2 & - & 1.85 & 10.91 \\
\hline 2 & $\begin{array}{c}\text { Jan. } 24 \text { to Feb. } \\
9\end{array}$ & 139 & $\begin{array}{l}\text { No. } 1 \text {, No. } 2 \text {, No. } 3 \text {, No. } 4 \text {, No. } 5 \text {, } \\
\text { No. } 6\end{array}$ & -53.71 & -58.57 \\
\hline 3 & $\begin{array}{c}\text { Feb. } 10 \text { to Feb. } \\
18\end{array}$ & 31 & No. 7 , No. 8 , No. 9 & -59.67 & -68.19 \\
\hline
\end{tabular}

TABLE 9: Impacts on traffic from COVID-19 and prevention policies.

capital, Kunming, suffered from the most severe pandemic, where the traffic dropped significantly; other regions with fewer confirmed cases also decreased at a similar level. This is because the government's goal is to eliminate the pandemic completely. Therefore, even if there are only a few cases, the local government would take active measures to avoid the spread of the pandemic locally. Even if there were no cases, such as in Diqing and Nujiang, the government prevented intercity travel.
The declines in highway traffic in Yunnan Province during the outbreak of COVID-19 were higher than those in some countries. For instance, in South Korea, the traffic on highways only fell by a maximum of $26.1 \%$ during the outbreak of COVID-19 [25]. In addition, the traffic in Yunnan Province decreased by about $23 \%$ in the first quarter of 2020 , but the number is only about $9.7 \%$ in South Korea [25]. First, the less decline in traffic is mainly caused by the less strict antipandemic policies. The antipandemic policies in South Korea 
included reducing outdoor activities, implementing a workfrom-home system in public organizations, encouraging private organizations to employ work-from-home systems, suggesting educational institutions to close, and delaying the commencement of schools [25]. Compared these policies with those in other countries, Yunnan Province performed stricter antipandemic policies which constrained all trips to entertainment venues, while the government of South Korea just recommended people reduce outdoor activities. Second, the less reduction may attribute to the different goals of pandemic prevention policies. The government of Yunnan Province tried to completely eliminate the pandemic to ensure that society was not affected by the outbreak. So, the government made efforts to prevent the spread of the pandemic, even adopting compulsory measures. The South Korean government tried to keep the number of cases at a low level to balance the pandemic and the smooth running of economic activities [41], which means most of the economic activities can still continue, and reducing travel is only an official recommendation rather than compulsory measures.

Although some countries have less traffic reduction, states and countries that have adopted strict antipandemic policies like Yunnan Province of China have also seen a sharp drop in traffic. For instance, a study from Somerville has shown a $71 \%$ drop in passenger vehicle traffic and a $46 \%$ drop in truck traffic after the implementation of business shutdowns and a state-wide stay-at-home order [42]. Similarly, a study in Portugal also showed a total reduction of around $70 \%$ in the level of highway traffic in the period of lockdown [43]. Therefore, strict antipandemic policies like stay-at-home order apparently affect highway traffic.

In addition, the impact of stay-at-home order on traffic also varied by regions. A study from North Carolina and Virginia of USA shows that the maximum reduction of traffic is around $40 \%$ after implementing the stay-at-home orders [28]. It is lower than the reduction of traffic in Yunnan. A study from Minnesota shows that the traffic volumes had recovered significantly before the stay-at-home order expired [21], which indicates some people might not follow the order.

In conclusion, the strict antipandemic policies like stayat-home order had a greater impact on traffic. By contrast, for countries that performed the slack antipandemic polices like recommendation for reducing outdoor activities, the reduction in traffic is relatively lower.

6.2. Impacts on Intercity Public Transportation. The impacts of COVID-19 on intercity bus service are significant. For instance, the traffic volume of intercity buses had For instance, the traffic volume of intercity buses decreased between $59.8 \%$ and $98.6 \%$ during the pandemic. Besides, people's use of intercity public transportation also decreased. Even though the intercity bus traffic only accounts for a smaller proportion of passenger vehicles on the highway, at an average of $1.8 \%$ before the pandemic, it fell to $0.8 \%$ during the pandemic, which means a $55.6 \%$ decline in intercity bus usage. Thus, it indicates that people were less likely to take intercity public transportation during the pandemic.
Several studies on public transportation have confirmed this tendency during the pandemic in other regions. For the developed country like Australia, service levels and public transportation schedules were unchanged during the COVID-19, but public transportation carriages and buses were almost empty [15]. In Santander, Spain, the use of public transportation decreased by 93\% [24]. However, in developing countries, a survey in Bangladesh showed that the percentage of passengers choosing public transportation to travel dropped from $37.06 \%$ to $19.58 \%$ during the pandemic [27]. Another study in China shows that public transportation usage decreased by $20.5 \%$, while private car usage increased by $6.4 \%$ [44].

By comparing these studies, it can be seen that the impacts of the pandemic on public transportation are not on the same level in developed and developing countries. The results show that public transportation usage declined more in developed countries. This may be due to the fact that private car ownership is higher in developed countries; thus, people can use private cars more often whereas, in developing countries, the decline in public transportation usage is much less compared with that in developed countries. Because more low-income people rely on public transport to travel in developing countries [27]. However, there is still an exception in Colombia. The demand reduction in most of the public transportation ranges from $80 \%$ to $90 \%$ [16], which mainly attributes to the reason that the public transportation lacked subsidy and most of them had to stop the operation [45].

All the above shreds of evidence reflect a crisis in public transportation under the COVID-19 pandemic. It should be noted that public transportation plays a crucial role in developing a green, low-carbon, and sustainable transportation system [46, 47]. Therefore, policies should be taken to ensure that public transportation can be maintained during the pandemic.

6.3. Impacts on Traffic Related to Economy. Cluster analysis showed that regions with low GDP per capita had less traffic reduction. In other words, the higher the GDP per capita, the greater impact of COVID-19 on traffic. During the pandemic, many people used telecommuting technology to work and have meetings [48], which vastly reduced the travel demand while keeping work and production on track. People with higher income are more likely to handle their work by telecommuting, while people in areas with low income are more likely to engage in jobs that need them to work on the site, such as agriculture and handicrafts.

The finding is consistent with the claim that traffic control practice cannot obtain a good effect in an area with low GDP per capita from another study [49]. Specifically, if the government wants to control the spread of the pandemic using traffic control, then it would be more effective to apply the policy in developed areas. Similarly, Loayza [50] claims in his study that blanket lockdown is less effective and more expensive in developing countries than in developed countries [50]. Therefore, inappropriate travel restrictions may cripple the economy and lead to a series of social problems [51]. 
These results also provide us with some insights. In developing countries, it should be more careful to adopt traffic control policies to stop the spread of pandemics. Overly strict traffic control policies may be more costly and not have the desired effect.

6.4. Recovery of Traffic. After the relaxation of strict antipandemic policies (e.g., reduction of the level of emergency response), traffic started to recover. The number of new confirmed cases declined to zero within two months from January $21^{\text {st }}$ of 2021 . Then, in the second quarter, traffic had fully recovered to prepandemic levels. It was found that the passenger vehicle traffic went through a total of four stages over 99 days under strict policies, including the Decline Stage, Rapid Recovery Stage, Slow Recovery Stage, and Normal Stage. The truck traffic only experienced the Decline Stage, Rapid Recovery Stage, and Normal Stage and took 51 days to recover. In addition, the impact of the pandemic on passenger and freight transportation continued throughout the year. Even by the end of 2020, the highway passenger-kilometers and tonne-kilometers of freight still had not recovered completely.

The government of Yunnan took strict antipandemic policy when the daily increase in new confirmed cases was only 25 , which caused the traffic to drop around $60 \%$. The drop in traffic is dramatic, but it did not take long to recover. There was an 18day Rapid Recovery Stage with a recovery rate of $15.6 \%$ per week, a 66-day Slow Recovery Stage with a recovery rate of $2.1 \%$ per week for passenger vehicles, and a 37-day Rapid Recovery Stage with a recovery rate of $12.9 \%$ per week for trucks. A similar study from South Korea shows that the average daily confirmed cases dropped from 4430 to 308 in March 2020 [25]. However, traffic did not recover significantly in March and fluctuated up and down around $-20 \%$ compared with traffic in 2019 [25]. Another study from North Carolina and Virginia shows an average recovery rate of traffic between $2.3 \%$ and $3.4 \%$ per week [28]. The traffic took 11 weeks (from the $15^{\text {th }}$ week to $26^{\text {th }}$ in 2020 ) to recover $25 \%$. This slow recovery may be due to the continued strict policies.

In summary, for Yunnan, where the number of confirmed cases was low, the recovery was rapid, despite the large drop in traffic after strict antipandemic policies. In contrast, recovery was relatively slow for countries or regions with a large number of confirmed cases. Therefore, it is still worthwhile to study in depth what kind of antipandemic measures such as traffic control should be implemented in different situations.

6.5. Policy Implications. From the above discussion, it is seen that the antipandemic policies have had a massive impact on highway traffic. Therefore, policymakers in the government need to be careful when they develop traffic control policies during the pandemic.

First of all, different purposes of traffic control need different strategies. If the purpose is to clear the pandemic completely, strict traffic control policies may only be applied when the pandemic has just started and the number of confirmed cases is small. For those aiming to control the number of confirmed cases at a low level, the traffic control policy would be more appropriate when the number of confirmed cases has increased dramatically. In developing countries, many developing country governments have implemented lockdown measures without sufficiently taking into account country-specific circumstances and other challenges [52]. If the outbreak is so severe that traffic control policies have to be applied, the control policies need to be adjusted timely according to the decline in traffic and the severity of the pandemic. It will help to strike a balance between economic development and pandemic prevention.

Second, monitoring of public transportation is also necessary. In developing countries, the share of public transportation is higher than in developed countries during the pandemic. Therefore, the hygiene of public transportation needs to be guaranteed. For example, policies on the hygiene issues of public transportation need to be released during the pandemic. Equipping public transportation with proper disinfection measures may reduce the risk of virus infection. In addition, public transportation can be significantly affected by the pandemic. Therefore, some policy support is needed to maintain the normal operation of public transportation. For instance, the policy can encourage people to use public transportation when the pandemic is under control.

Third, the time required for traffic to recover to normal levels is long, especially after successive strict traffic control policies. Therefore, to ensure that normal travel activities are not affected for a long time, the duration of traffic control needs to be reasonably controlled, avoiding the low rate of traffic recovery.

Therefore, when developing traffic control measures to control the pandemic, the severity of the local pandemic and the level of economic development need to be considered; and timely policy adjustments are necessary. It is the key to balancing pandemic control and social development.

\section{Conclusions}

The COVID-19 pandemic had a significant impact on highway traffic. This paper investigated the impacts of COVID-19 on highway traffic in the entire process from the beginning with a sudden drop to a gradual return to normal. First, the paper examined the province-wide traffic variation during the first 40 days of the outbreak. Second, the paper studied the intercity bus traffic variation and intercity bus usage. Third, the paper investigated the extent to which traffic in different regions was affected under different levels of socio-economic development using cluster analysis. Finally, the paper showed the process of traffic recovery and verified the recovery of traffic volume using hypothesis testing. The findings in this study include the following:

(i) Under the antipandemic policy, a significant decline in highway traffic occurred in all regions, regardless of the severity of the pandemic in each region.

(ii) When the pandemic was most severe during the outbreak, passenger vehicle traffic and truck traffic dropped by $59.67 \%$ and $68.19 \%$, respectively. 
(iii) The intercity public transportation on highways declined by $-59.8 \%$ to $-98.6 \%$ in different regions; the intercity bus usage dropped by $55.6 \%$.

(iv) Traffic declined approximately by $23 \%$ in the first quarter of 2020 . The AADTs of passenger vehicles and trucks decreased by $6 \%$ and $3 \%$ throughout the year, respectively.

(v) By comparing traffic volumes in different regions, it is found that the higher the GDP per capita, the greater impact of COVID-19 on traffic. For regions with lower GDP per capita, traffic volume changes were minor.

(vi) Under strict antipandemic policies, the passenger vehicle traffic went through four stages: the Decline Stage, Rapid Recovery Stage, Slow Recovery Stage, and Normal Stage. Traffic eventually returned to prepandemic levels in 99 days.

(vii) Truck traffic only experienced the Decline Stage, Rapid Recovery stage, and Normal Stage and took 51 days to recover to the Normal stage.

(viii) In Rapid Recovery Stage, the recovery rates were $15.6 \%$ and $12.9 \%$ per week for passenger vehicles and trucks, respectively, while the recovery rate was $2.1 \%$ for passenger vehicles in the Slow Recovery Stage.

(ix) Despite the recovery of traffic volumes, neither passenger-kilometers nor tonne-kilometers of freight in 2020 returned to the same level as in 2019.

These findings are valuable references for decision-makers to develop sound antipandemic policies. The valuable findings provided in this paper would help researchers understand the impact of the pandemic better. The clustering method used in this paper can also be applied to other countries or cities to reveal further the impact of antipandemic policies on traffic at different levels of socio-economic development. Although the above findings provide valuable information for policy development and policy study in developing countries, this study has some limitations. First, the paper did not show the change in the trip distribution due to the lack of road users' origin-destination data. Second, only traffic count data have been used for analysis instead of traffic demand investigation. Third, the results of the current study on the extent to which traffic was affected in regions with different socio-economic levels include only 16 regions in Yunnan, and the information reflected in the results is limited. Therefore, further study needs to be focused on the trip spatial distribution and modeling the relationship between traffic variations and levels of economic development economic levels of regions. In addition, the strict antipandemic policies can inevitably lead to a significant drop in traffic. On the other hand, the lenient policy will not be able to end the pandemic and may affect traffic for a longer time. How to strike a balance is open to debate.

\section{Data Availability}

The traffic count station data used to support the findings of this study are available from the corresponding author upon request. The COVID-19 case data and socio-economic data used in this study are obtained from a public website and can also be available from the corresponding author upon request.

\section{Conflicts of Interest}

The authors declare that there are no conflicts of interest regarding the publication of this article.

\section{Acknowledgments}

This work was supported by the Department of Transport of Yunnan Province and Technology (grant number [2020]152); the National Natural Science Foundation of China (grant nos. 51308335 and 71871029); the 111 project of Sustainable Development of Transportation in Western Urban Agglomeration (grant no. B20035); and the Natural Science Foundation of Shaanxi Province (grant no. 2021JQ-293).

\section{References}

[1] A. Sharifi and A. R. Khavarian-Garmsir, "The COVID-19 pandemic: impacts on cities and major lessons for urban planning, design, and management," The Science of the Total Environment, vol. 749, Article ID 142391, 2020.

[2] WHO, COVID-19 Weekly Epidemiological Update 22, World Health Organization, Geneva, Switzerland, 2021.

[3] T. Burki, "China's successful control of COVID-19," The Lancet Infectious Diseases, vol. 20, no. 11, pp. 1240-1241, 2020.

[4] J. Y. Choi, "COVID-19 in South Korea," Postgraduate Medical Journal, vol. 96, no. 1137, pp. 399-402, 2020.

[5] M. Her, "How is COVID-19 affecting South Korea? What is our current strategy?" Disaster Medicine and Public Health Preparedness, vol. 14, no. 5, pp. 684-686, 2020.

[6] D. Muley, M. S. Ghanim, A. Mohammad, and M. Kharbeche, "Quantifying the impact of COVID-19 preventive measures on traffic in the state of Qatar," Transport Policy, vol. 103, pp. $45-59,2020$.

[7] WHO, "Coronavirus Disease (Covid-19) Advice for the public," 2021, https:/www.who.int/emergencies/diseases/ novel-coronavirus-2019/advice-for-public.

[8] J. Zhang, B. Feng, Y. Wu, P. Xu, and N. Dong, "The effect of human mobility and control measures on traffic safety during COVID-19 pandemic," PLoS One, vol. 16, no. 3, Article ID e0243263, 2021.

[9] C. Chen, C. B. Frey, and G. Presidente, "Culture and contagion: individualism and compliance with COVID-19 policy," Journal of Economic Behavior \& Organization, vol. 190, pp. 191-200, 2021.

[10] S. Parr, B. Wolshon, and J. Renne, "Traffic impacts of the COVID-19 pandemic: statewide analysis of social separation and activity restriction," Natural Hazards Review, vol. 21, no. 3, Article ID 04020025, 2020.

[11] Y. Kang, S. Gao, Y. Liang, M. Li, J. Rao, and J. Kruse, "Multiscale dynamic human mobility flow dataset in the U.S. during the COVID-19 epidemic," Scientific Data, vol. 7, no. 1, p. $390,2020$.

[12] Ò. Saladié, E. Bustamante, and A. Gutiérrez, "COVID-19 lockdown and reduction of traffic accidents in Tarragona province, Spain," Transportation research interdisciplinary perspectives, vol. 8, Article ID 100218, 2020. 
[13] J. Lee and M. Abdel-Aty, Changes in Traffic Crash Patterns: Before and after the Outbreak of COVID-19 in Southern Florida, Transportation Research Board, Washington, DC, USA, 2021.

[14] J. Lee, F. Baig, and A. Pervez, "Impacts of COVID-19 on individuals' mobility behavior in Pakistan based on self-reported responses," Journal of Transport \& Health, vol. 22, Article ID 101228, 2021.

[15] M. J. Beck and D. A. Hensher, "Insights into the impact of COVID-19 on household travel and activities in Australia-the early days of easing restrictions," Transport Policy, vol. 99, pp. 95-119, 2020.

[16] J. Arellana, L. Márquez, and V. Cantillo, "COVID-19 outbreak in Colombia: an analysis of its impacts on transport systems," Journal of Advanced Transportation, vol. 2020, Article ID 8867316, 16 pages, 2020.

[17] H. Zhou, Y. Wang, J. R. Huscroft, and K. Bai, "Impacts of COVID-19 and anti-pandemic policies on urban transport-an empirical study in China," Transport Policy, vol. 110, pp. 135-149, 2021.

[18] J. Yu, N. Xie, J. Zhu, Y. Qian, S. Zheng, and X. Chen, "Exploring impacts of COVID-19 on city-wide taxi and ridesourcing markets: evidence from Ningbo, China," Transport Policy, vol. 115, pp. 220-238, 2022.

[19] X. Jiang, W. Wei, S. Wang, T. Zhang, and C. Lu, "Effects of COVID-19 on urban population flow in China," International Journal of Environmental Research and Public Health, vol. 18, no. 4, p. 1617, 2021.

[20] N. Jiang, S. Li, and S. Cao, "Transportation activity patterns of Chinese population during the COVID-19 epidemic," Research of Environmental Sciences, vol. 33, no. 7, pp. 1675-1682, 2020.

[21] Z. Liu and R. Stern, "Quantifying the traffic impacts of the COVID-19 shutdown," Journal of Transportation Engineering, Part A: Systems, vol. 147, no. 5, Article ID 04021014, 2021.

[22] L. Dong, Y. Lv, H. Sun, D. Zhi, and T. Chen, "GPS trajectorybased spatio-temporal variations of traffic accessibility under public health emergency consideration," Journal of Advanced Transportation, vol. 2021, Article ID 8854451, 22 pages, 2021.

[23] E. Pepe, P. Bajardi, and L. Gauvin, "COVID-19 outbreak response: a first assessment of mobility changes in Italy following national lockdown," Scientific Data, vol. 7, no. 1, pp. 1-16, 2020.

[24] A. Aloi, B. Alonso, and J. Benavente, "Effects of the COVID19 lockdown on urban mobility: empirical evidence from the city of Santander (Spain)," Sustainability, vol. 12, no. 9, 2020.

[25] H. Lee, S. J. Park, G. R. Lee et al., "The relationship between trends in COVID-19 prevalence and traffic levels in South Korea," International Journal of Infectious Diseases, vol. 96, pp. 399-407, 2020.

[26] M. Simunek, Z. Smutny, and M. Dolezel, "The impact of the COVID-19 movement restrictions on the road traffic in the Czech republic during the state of emergency," Journal of Advanced Transportation, vol. 2021, Article ID 6622028, 20 pages, 2021.

[27] N. Anwari, M. Tawkir Ahmed, M. Rakibul Islam, M. Hadiuzzaman, and S. Amin, "Exploring the travel behavior changes caused by the COVID-19 crisis: a case study for a developing country," Transportation Research Interdisciplinary Perspectives, vol. 9, Article ID 100334, 2021.

[28] B. Goenaga, N. Matini, D. Karanam, and B. S. Underwood, "Disruption and recovery: initial assessment of COVID-19 traffic impacts in North Carolina and Virginia," Journal of
Transportation Engineering, Part A: Systems, vol. 147, no. 4, Article ID 06021001, 2021.

[29] K. Alsabti, S. Ranka, and V. Singh, "An efficient k-means clustering algorithm," Electrical Engineering and Computer Science, vol. 43, 1997.

[30] G. Tzortzis and A. Likas, "The global kernel k-means clustering algorithm," in Proceedings of the 2008 IEEE International Joint Conference on Neural Networks (IEEE World Congress on Computational Intelligence), pp. 1977-1984, IEEE, Hong Kong, China, June 2008.

[31] E. Kaygin and E. Topçuoğlu, "The effects of COVID-19 pandemic upon tourism: a sample from the city of Kars," Mehmet Akif Ersoy Üniversitesi İktisadi ve İdari Bilimler Fakültesi Dergisi, vol. 7, no. 3, pp. 782-805, 2020.

[32] Yunnan Provincial Bureau of Statistics, Yunnan National Economy and Social Development Statistical Bulletin 2020, Yunnan Provincial Bureau of Statistics, Yunnan, China, 2021.

[33] J. A. Rice, "Mathematical statistics and data analysis," Cengage Learning, Boston, MA, USA, 2006.

[34] Yunnan Provincial Bureau of Statistics, "Main data of the seventh national population census of Yunnan province," 2021, http://stats.yn.gov.cn/phone/tjsj/jjxx/202105/ t20210517_1051976.html.

[35] Q. Bai, A. Ahmed, S. Labi, and K. C. Sinha, "Traffic volume benchmarks for major arterial widening versus expressway construction: exploratory approach," Journal of Transportation Engineering, Part A: Systems, vol. 143, no. 8, Article ID 04017040, 2017.

[36] Yunnan Provincial Bureau of Statistics, Yunnan Provincial Statistical Yearbook, Yunnan Provincial Bureau of Statistics, Yunnan, China, 2021.

[37] National Health Commission of the People's Republic of China, "Notification of COVID-19," 2020, http://http//www. nhc.gov.cn/xcs/yqtb/list_gzbd.shtml.

[38] People's Government of Yunnan Province, "COVID-19 prevention and control policies," 2020, http://www.yn.gov.cn/ ztgg/yqfk/zcfk/index_10.html.

[39] Q. Bai, M. Miralinaghi, S. Labi, and K. C. Sinha, "Methodology for analyzing the trade-offs associated with multi-objective optimization in transportation asset management under uncertainty," Computer-Aided Civil and Infrastructure Engineering, vol. 36, no. 4, pp. 381-401, 2021.

[40] J. Zhang, Y. Hayashi, and L. D. Frank, "COVID-19 and transport: findings from a world-wide expert survey," Transport Policy, vol. 103, pp. 68-85, 2021.

[41] Z. Liu, P. Magal, and G. Webb, "Predicting the number of reported and unreported cases for the COVID-19 pandemics in China, South Korea, Italy, France, Germany and United Kingdom," Journal of Theoretical Biology, vol. 509, Article ID 110501, 2021.

[42] N. Hudda, M. C. Simon, A. P. Patton, and J. L. Durant, "Reductions in traffic-related black carbon and ultrafine particle number concentrations in an urban neighborhood during the COVID-19 pandemic," The Science of the Total Environment, vol. 742, Article ID 140931, 2020.

[43] C. O. Cruz and J. M. Sarmento, "The impact of COVID-19 on highway traffic and management: the case study of an operator perspective," Sustainability, vol. 13, no. 9, Article ID 5320, 2021.

[44] J. Zhang and J. Lee, "Interactive effects between travel behaviour and COVID-19: a questionnaire study," Transportation Safety and Environment, vol. 2021, Article ID tdab003, 2021. 
[45] D. Toro-González, V. Cantillo, and V. Cantillo-García, "Factors influencing demand for public transport in Colombia," Research in Transportation Business \& Management, vol. 36, Article ID 100514, 2020.

[46] B. van Wee and F. Witlox, "COVID-19 and its long-term effects on activity participation and travel behaviour: a multiperspective view," Journal of Transport Geography, vol. 95, Article ID 103144, 2021.

[47] Q. Bai, A. Ahmed, Z. Li, and S. Labi, "A hybrid pareto frontier generation method for trade-off analysis in transportation asset management," Computer-Aided Civil and Infrastructure Engineering, vol. 30, no. 3, pp. 163-180, 2015.

[48] D. A. Hensher, M. J. Beck, and E. Wei, "Working from home and its implications for strategic transport modelling based on the early days of the COVID-19 pandemic," Transportation Research Part A: Policy and Practice, vol. 148, pp. 64-78, 2021.

[49] S. Lin, J. Huang, Z. He, and D. Zhan, "Which measures are effective in containing COVID-19? Empirical research based on prevention and control cases in China," 2020.

[50] N. Loayza, "Costs and trade-offs in the fight against the COVID-19 pandemic: a developing country perspective," World Bank Research and Policy Briefs, vol. 2020, Article ID 148535, 2020.

[51] M. Batool, H. Ghulam, M. A. Hayat et al., "How COVID-19 has shaken the sharing economy? An analysis using Google trends data," Economic Research-Ekonomska Istraživanja, vol. 34, no. 1, pp. 2374-2386, 2020.

[52] A. Z. Chowdhury and K. S. Jomo, "Responding to the COVID-19 pandemic in developing countries: lessons from selected countries of the global south," Development, vol. 63, no. 2, pp. 162-171, 2020. 